University of Nebraska - Lincoln

DigitalCommons@University of Nebraska - Lincoln

$10-2013$

\title{
Improving the Sweeping Efficiency of Permanganate into Low Permeable Zones To Treat TCE: Experimental Results and Model Development
}

\author{
Chanat Chokejaroenrat \\ Suranaree University of Technology, Thailand \\ Negin Kananizadeh \\ University of Nebraska-Lincoln, nkananizadeh2@unl.edu \\ Chainarong Sakulthaew \\ Kasetsart University, Bangkok, Thailand \\ Steve D. Comfort \\ University of Nebraska-Lincoln, scomfort1@unl.edu \\ Yusong Li \\ University of Nebraska-Lincoln, yli7@unl.edu
}

Follow this and additional works at: https://digitalcommons.unl.edu/watercenterpubs

Part of the Environmental Chemistry Commons, and the Environmental Engineering Commons

Chokejaroenrat, Chanat; Kananizadeh, Negin; Sakulthaew, Chainarong; Comfort, Steve D.; and Li, Yusong, "Improving the Sweeping Efficiency of Permanganate into Low Permeable Zones To Treat TCE: Experimental Results and Model Development" (2013). Faculty Publications from The Water Center. 26. https://digitalcommons.unl.edu/watercenterpubs/26

This Article is brought to you for free and open access by the Water Center, The at DigitalCommons@University of Nebraska - Lincoln. It has been accepted for inclusion in Faculty Publications from The Water Center by an authorized administrator of DigitalCommons@University of Nebraska - Lincoln. 


\title{
Improving the Sweeping Efficiency of Permanganate into Low Permeable Zones To Treat TCE: Experimental Results and Model Development
}

\author{
Chanat Chokejaroenrat, ${ }^{1,2}$ Negin Kananizadeh, ${ }^{1}$ Chainarong Sakulthaew, ${ }^{3,4}$ Steve Comfort, ${ }^{3}$ and \\ Yusong $\mathrm{Li}^{1}$ \\ 1. Department of Civil Engineering, University of Nebraska-Lincoln, Lincoln, Nebraska 68588-0531, USA \\ 2. School of Environmental Engineering, Institute of Engineering, Suranaree University of Technology, Nakhon Ratchasima, \\ Thailand 30000 \\ 3. School of Natural Resources, University of Nebraska-Lincoln, Lincoln, Nebraska 68583-0915, USA \\ 4. Department of Veterinary Technology, Faculty of Veterinary Technology, Kasetsart University, Bangkok, Thailand 10900
}

Corresponding author - S. Comfort, tel 402 472-1502, fax: 402 472-7904, email scomfort@unl.edu

\begin{abstract}
The residual buildup and treatment of dissolved contaminants in low permeable zones (LPZs) is a particularly challenging issue for injectionbased remedial treatments. Our objective was to improve the sweeping efficiency of permanganate into LPZs to treat dissolved-phase TCE. This was accomplished by conducting transport experiments that quantified the ability of xanthan- $\mathrm{MnO}_{4}^{-}$solutions to penetrate and cover (i.e., sweep) an LPZ that was surrounded by transmissive sands. By incorporating the non-Newtonian fluid xanthan with $\mathrm{MnO}_{4}^{-}$, penetration of $\mathrm{MnO}_{4}^{-}$into the LPZ improved dramatically and sweeping efficiency reached $100 \%$ in fewer pore volumes. To quantify how xanthan improved TCE removal, we spiked the LPZ and surrounding sands with ${ }^{14} \mathrm{C}$-lableled TCE and used a multistep flooding procedure that quantified the mass of ${ }^{14} \mathrm{C}$-TCE oxidized and bypassed during treatment. Results showed that TCE mass removal was 1.4 times greater in experiments where xanthan was employed. Combining xanthan with $\mathrm{MnO}_{4}{ }^{-}$also reduced the mass of TCE in the LPZ that was potentially available for rebound. By coupling a multiple species reactive transport model with the Brinkman equation for nonNewtonian flow, the simulated amount of ${ }^{14} \mathrm{C}$-TCE oxidized during transport matched experimental results. These observations support the use of xanthan as a means of enhancing $\mathrm{MnO}_{4}{ }^{-}$delivery into LPZs for the treatment of dissolved-phase TCE.
\end{abstract}

\section{Introduction}

Removing chlorinated solvents from contaminated groundwater is recognized as one of the most difficult problems associated with groundwater pollution. ${ }^{1}$ Research results from the last 30 years have shown that past pump and treat approaches as well as many other in situ treatments have failed to restore complex aquifers back to drinking water standards. ${ }^{2-4}$ Remedial approaches like in situ chemical oxidation (ISCO) by permanganate $\left(\mathrm{MnO}_{4}^{-}\right)$have been used for some time, but the success of this approach depends upon whether the oxidant comes in contact with the chlorinated solvents. This in turn is dependent upon the heterogeneity of the aquifer and whether the oxidant effectively sweeps or covers the intended target zone.

Contaminants migrating from DNAPL source zones will often diffuse from transmissive regions into low permeable zones (LPZs). This residual buildup of dissolved contaminants in LPZs over time becomes particularly challenging for ISCO treatments because these less permeable areas are usually bypassed during treatment. Moreover, once the injected oxidant has traversed the transmissive zones, contaminants in LPZs will eventually diffuse back into the surrounding higher permeability flow zones via matrix diffusion, a process known as rebound and one that has been documented to occur at numerous ISCO sites. ${ }^{5-12}$

To address the treatment of chlorinated solvents in LPZs, shear-thinning polymers have been used as a coinjected remedial agent to increase the viscosity of the displacing fluid. ${ }^{13-20}$ By increasing viscosity, fluid mobility in higher permeable strata is reduced, and this reduction in mobility promotes cross-flow into adjacent lower permeable strata. The net result is a more unified coverage of the injected fluid across heterogeneous formations. ${ }^{20-22}$ Although several researchers 
have documented the success of using shear-thinning polymers, like xanthan, to combat the heterogeneity-induced bypassing of surfactants (e.g., References 13-20), the coupling of shear-thinning polymers with oxidants for use in ISCO applications has received less attention. Smith et al. ${ }^{23}$ provided the first evidence that xanthan was compatible with permanganate and could be used as a polymer-enhanced chemical oxidation treatment for PCE. Their research provided important groundwork for further studies aimed at chemically oxidizing chlorinated solvents in low permeable zones. McCray et al. 24 showed that xanthan increased the sweeping efficiency of $\mathrm{MnO}_{4}{ }^{-}$into LPZs (containing nonaqueous phase PCE) and improved the percentage of PCE oxidized, which they inferred by the moles of $\mathrm{MnO}_{4}{ }^{-}$consumed.

In this present study, we quantified how xanthan directly improved the permanganate-induced oxidation of TCE during transport by using a two-dimensional (2D) flow cell containing transmissive and low permeable zones that were spiked with dissolved-phase ${ }^{14} \mathrm{C}$-TCE. Our objective was to improve the sweeping efficiency of $\mathrm{MnO}_{4}{ }^{-}$into low permeable zones to treat TCE and reduce the potential for rebound. This was accomplished by determining the viscosity-shear rate relationship of various $\mathrm{MnO}_{4}$-xanthan solutions and then conducting multiple transport experiments where injection volumes and $\mathrm{MnO}_{4}$-xanthan concentrations were varied. The criteria used to evaluate the various $\mathrm{MnO}_{4}$-xanthan treatments included visual coverage of the LPZ (via time lapse photography), the percentage of ${ }^{14} \mathrm{C}$-labeled TCE oxidized in the effluent, and the amount of TCE bypassed during treatment. Experimental results were then used in model development where we coupled a multiple species reactive transport model with the Brinkman equation for non-Newtonian flow to simulate the oxidation of ${ }^{14} \mathrm{C}-\mathrm{TCE}$ during transport.

\section{Materials and Methods}

Experimental details on rheology measurements (i.e., viscosity-shear rate relationships) and how the temporal stability of xanthan- $\mathrm{MnO}_{4}{ }^{-}$solutions was quantified are provided in the Supporting Information (SI). Materials and methods used in the transport experiments including construction of the 2D tank (Figure SI-1), chemicals (Table S1) and soils used, procedures to create transmissive and low permeable zones, and sampling protocol of $2 \mathrm{D}$ tank effluent are also provided in the Supporting Information.

Transport Experiments. Prior to flooding the 2D tank, we exchanged the air space in the tank with $\mathrm{CO}_{2}$ for $60 \mathrm{~min}$. This prevented entrapped air pockets from forming in the tank during flooding. ${ }^{25}$ All transport experiments started by flooding the tank with dissolved-phase TCE $\left(500 \mathrm{mg} \mathrm{L}^{-1}\right)$, which was prepared and stirred at least $24 \mathrm{~h}$ prior to use. We used a 3-L collapsible (i.e., zero headspace) Tedlar bag (Zefon, Ogala, FL) ${ }^{26}$ equipped with a stainless steel valve fitting to minimize TCE volatilization and adsorption. In all transport experiments, solutions were spiked with ${ }^{14} \mathrm{C}$-TCE $\left({ }^{14} \mathrm{C}\right.$-uniformly labeled-TCE, Moravek Biochemicals, Brea, CA, specific activity: $5 \mathrm{mCi} \mathrm{mmol}^{-1}$ ) to produce an initial activity of $2500 \mathrm{dpms} \mathrm{mL}^{-}$ ${ }^{1}$. Inlet flow into the 2D-tank was controlled by a HPLC pump at a consistent flow rate of $3 \mathrm{~mL} \mathrm{~min}{ }^{-1}$. Given the pore volume (PV) of the tank and a flow rate of $3 \mathrm{~mL} \mathrm{~min}^{-1}$, the time for one pore volume to pass through the column was approximately 163 min. After 5 PV of solution had passed through the tank, multiple effluent samples were collected and analyzed to confirm consistency in ${ }^{14} \mathrm{C}$-activity.
Initial floods of xanthan and $\mathrm{MnO}_{4}^{-}$were prepared $2 \mathrm{~h}$ prior to the start of the experiments. Two types of flooding procedures were used in our transport experiments, namely, a conventional flood and multiple-step flooding procedure (Table S2).

In a conventional flood, the 2D-tank received either $2 \mathrm{PV}$ (Exps. 1A-1B) or 0.5 PV of an initial flood (Exps. 1C-1F). The initial eluent was either (i) $441 \mathrm{mg} \mathrm{L}^{-1}(3 \mathrm{mM}) \mathrm{CaCl}_{2} \cdot \mathrm{H}_{2} \mathrm{O}$ (dyed red with 5\% (v/v) food dye; $\operatorname{Exp} 1 \mathrm{~A}$ ) and mixed with $500 \mathrm{mg} \mathrm{L}^{-1}$ of xanthan; (ii) $4000 \mathrm{mg} \mathrm{L}^{-1} \mathrm{MnO}_{4}^{-}$(Exps. 1B1C); or (iii) $4000 \mathrm{mg} \mathrm{L}^{-1} \mathrm{MnO}_{4}^{-}$with varied concentrations of xanthan (Exps. 1D-1F; Table S2). After 0.5 PV had been injected into the $2 \mathrm{D}$ tank for experiments $1 \mathrm{C}-1 \mathrm{~F}$, the eluent was switched to a background concentration $\left(\mathrm{CaCl}_{2}\right.$ solution; 441 $\mathrm{mg} \mathrm{L}^{-1}$ ) which was used to simulate groundwater flow for 1.50 PV. A digital camera (Canon 870 IS) was used to record solute movement and coverage of the LPZ.

Six additional experiments (Exps. 2A-2F) were conducted using multiple-step flooding (Table S2). The experimental sequence consisted of three stages: an initial flood $(0.25 \mathrm{PV})$, a secondary flood (2.75 PV), and a mobilization flood (1.50 PV) for a total of $4.50 \mathrm{PV}$. A $500 \mathrm{mg} \mathrm{L}^{-1}$ xanthan solution was prepared from the stock solution and mixed with either $\mathrm{MnO}_{4}^{-}$ or $\mathrm{CaCl}_{2}$ for the initial flood. After $0.25 \mathrm{PV}$ of initial flood, eluent was switched to a secondary flood of $\mathrm{CaCl}_{2}$ for $2.75 \mathrm{PV}$. Then, a $500 \mathrm{mg} \mathrm{L}^{-1}$ xanthan solution was used as a mobilization flood to displace any residual dissolve-phase TCE left (i.e., bypassed) in the 2D tank (with the exception of Exp. 2B, which used $\mathrm{H}_{2} \mathrm{O}$ ). Time lapse photography was again used to record solute movement.

Sample Collection Protocol. In the multiple-step flooding experiments, we monitored the eluent for changes in ${ }^{14} \mathrm{C}$-activity. Once the transport experiment began, effluent samples were periodically collected every 15 to $45 \mathrm{~min}$ with gastight Luerlock needles fitted to the exit sampling ports. We used the procedures of Kriegman-King and Reinhard, ${ }^{27}$ to differentiate between ${ }^{14} \mathrm{C}-\mathrm{TCE},{ }^{14} \mathrm{C}$-degradation products, and ${ }^{14} \mathrm{CO}_{2}$. Details of those procedures are provided in the Supporting Information.

\section{Model Development}

Flow Model. Flows of xanthan and the xanthan- $\mathrm{MnO}_{4}^{-}$solution were simulated by coupling the Brinkman equation ${ }^{28}$ (Equation 1) with the continuity equation (Equation 2). The Brinkman equation is a generalization of Darcy's law, which accounts for the production of an effective viscosity ${ }^{29}$ and has previously been used to simulate non-Newtonian flow in porous medium. ${ }^{30}$

$$
\begin{aligned}
& \frac{\rho}{n} \frac{\mathrm{d} \vec{u}}{\mathrm{~d} t}=\nabla \cdot\left[-P+\frac{\mu}{n}\left(\nabla \vec{u}+(\nabla \vec{u})^{T}\right)-\frac{2 \mu}{3 n}(\nabla \cdot \vec{u})\right]-\frac{\mu}{k} \vec{u}+\vec{F} \\
& \nabla \cdot(\rho \vec{u})=0
\end{aligned}
$$

Here, $P$ is the pressure $[\mathrm{Pa}], \vec{u}$ is the velocity vector $[\mathrm{m} / \mathrm{s}], \mu$ is the viscosity of the fluid $[\mathrm{Pa} \cdot \mathrm{s}], k$ is the permeability of the porous media $\left[\mathrm{m}^{2}\right], n$ is the porosity, and $\vec{F}$ is the volume force $\left[\mathrm{kg} /\left(\mathrm{m}^{2} \cdot \mathrm{s}^{2}\right)\right]$, which, in this case, is gravity.

Both xanthan and the xanthan- $\mathrm{MnO}_{4}^{-}$solution were observed as shear-thinning non-Newtonian fluids, where viscosity changes with the shear rate of flow. Therefore, fluid viscosity was considered a function of shear rate and polymer 
concentration following a power law model (Equation 3) 16,31

$$
\mu=\max \left(\mu_{\infty^{\prime}} \min \left(a\left(C_{1} / C_{10}\right) \gamma^{b}, \mu_{0}\right)\right)
$$

where $a$ and $b$ are power law model constants; $\mu_{\infty}$ and $\mu_{0}$ are the fluid viscosity parameters at high $\left(\mu_{\infty}\right)$ and low shear rates $\left(\mu_{0}\right) ; C_{1} / C_{10}$ (unit: $\mathrm{kg} / \mathrm{m}^{3}$ ) is the normalized polymer concentration; and $\gamma$ is the shear rate (Equation 4$):^{13}$

$$
\gamma=\frac{2.4 u}{\sqrt{k n}}
$$

Here, $u$ is the magnitude of the velocity vector $\vec{u}$. When the xanthan- $\mathrm{MnO}_{4}{ }^{-}$solution was injected, the influence of $\mathrm{MnO}_{4}^{-}$concentration on the fluid viscosity was considered by including a normalized $\mathrm{MnO}_{4}{ }^{-}$concentration term $C_{2} / C_{20}$ (unit: $\mathrm{kg} / \mathrm{m}^{3}$ ):

$$
\mu=\max \left(\mu_{\infty^{\prime}} \min \left(a\left(C_{1} / C_{10}\right)\left(C_{2} / C_{20}\right) r^{b}, \mu_{0}\right)\right)
$$

For both Equations 3 and 5, $\mu_{\infty}$ was equal to the viscosity of water. Parameters $a, b$, and $\mu_{0}$ were estimated by fitting the measured shear rate and viscosity data for shear rate less than $6 \mathrm{~s}^{-1}$, using the power law model (Equation 3). Focusing on this region allowed us to overcome the numerical problems associated with the extremely steep reduction in viscosity at high shear rates. In all the experiments, simulated shear rate was generally less than $6 \mathrm{~s}^{-1}$. For the xanthan- $\mathrm{MnO}_{4}^{-}$solution, $\mu_{0}$ was treated as a function of $\mathrm{MnO}_{4}^{-}$, by fitting the measured viscosity at a shear rate of $0.1 \mathrm{~s}^{-1}$ to the $\mathrm{MnO}_{4}^{-}$concentration:

$$
\mu_{0}=0.0876 \times C_{2}+0.24
$$

The values for variables $a, b$, and $\mu_{0}$ are listed in the Supporting Information (Table S3).

Transport Model. Advection dispersion reaction (ADR) equation for multiple species transport was used to simulate solute transport and reaction:

$$
\frac{\partial C_{i}}{\partial t}=-\frac{u}{n} \cdot C_{i}+\nabla \cdot\left(D \nabla C_{i}\right)+R_{i}
$$

where $C$ is the concentration of the species $\left(\mathrm{kg} / \mathrm{m}^{3}\right), D$ is dispersion coefficient $\left(\mathrm{m}^{2} / \mathrm{s}\right), R$ is the reaction rate $\left[\mathrm{kg} /\left(\mathrm{m}^{3} \mathrm{~s}\right)\right]$, and $i$ represents the simulated species, including xanthan, $\mathrm{MnO}_{4}^{-}, \mathrm{TCE}$, and a lumped reaction product. No reaction was applied to xanthan. A second order reaction was considered for the $\mathrm{MnO}_{4}^{-}$and TCE reaction:

$$
\frac{\mathrm{d} C_{\mathrm{TCE}}}{\mathrm{d} t}=-k \times C_{\mathrm{TCE}} \times C_{\mathrm{MnO}_{4}^{-}}
$$

Here, $k$ is the second order reaction rate constant $\left[\mathrm{m}^{3} /\right.$ $(\mathrm{kg} \cdot \mathrm{s})]$. The same rate value was applied for the generation of a lumped reaction product. Details of model implementation including software used and boundary conditions imposed are provided in the Supporting Information.

\section{Results and Discussion}

$\mathrm{MnO}_{4}^{-}$Effects on Xanthan Viscosity. Previous researchers have observed an increase in viscosity with increasing xanthan concentrations ${ }^{19,20}$ attributed in part to the intermolecular interaction that increases the macromolecule dimensions. ${ }^{18,} 32$ Results from our viscometer experiments also showed that

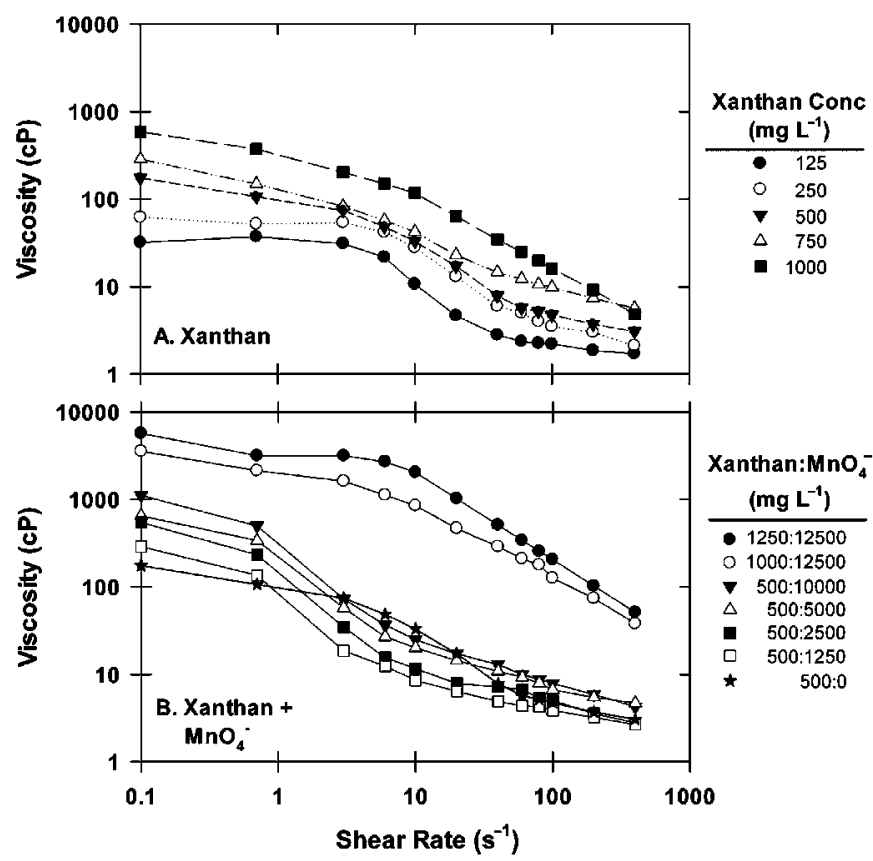

Figure 1. Viscosity-shear rate relationship for various concentrations of $(A)$ xanthan and (B) $\mathrm{MnO}_{4}^{--}$-xanthan.

increasing xanthan concentrations increased the solution viscosity across all shear rates (Figure 1A). At xanthan concentrations of 125 or $250 \mathrm{mg} \mathrm{L}^{-1}$, viscosities were relatively constant at shear rates less than $3 \mathrm{~s}^{-1}$ (i.e., Newtonian plateau); at higher shear rates, viscosities decreased with increasing shear rates (Figure 1A). Differences in viscosities among xanthan solution concentrations were most evident at low versus high shear rates. For example, at the $3 \mathrm{~s}^{-1}$ shear rate, viscosities spanned several hundred centipoise $(\mathrm{cP})$, whereas at the shear rate of $200 \mathrm{~s}^{-1}$, the viscosities of all solutions were $\leq 10 \mathrm{cP}$ (Figure 1).

To determine how $\mathrm{MnO}_{4}^{-}$concentrations influenced the viscosity-shear rate relationship, a $500 \mathrm{mg} \mathrm{L}^{-1}$ xanthan solution was mixed with varying $\mathrm{MnO}_{4}^{-}$concentrations (1250-10000 $\mathrm{mg} \mathrm{L}^{-1}$ ), and viscosities were measured immediately. Results showed that increasing $\mathrm{MnO}_{4}^{-}$concentrations increased the apparent viscosity of the solution in both Newtonian and nonNewtonian flow regions (Figure 1B). As observed with xanthan alone, treatment differences were more pronounced at low shear rates. Collectively, viscosity measurements for xanthan solutions tested with and without $\mathrm{MnO}_{4}^{-}$(Figure 1B) showed that xanthan was compatible with $\mathrm{MnO}_{4}^{-}$, and overall a similar viscosity-shear rate relationship was observed.

When higher $\mathrm{MnO}_{4}^{-}$and xanthan concentrations were both used (12500 mg L-1 $\mathrm{MnO}_{4}^{-} ; 1000$ or $1250 \mathrm{mg} \mathrm{L}^{-1}$ xanthan), viscosities values were the highest recorded (Figure 1B). Although the increased salinity of additional mono- and bivalent cations have been shown to decrease polymer solution viscosity, ${ }^{13}$ especially at high shear rates $\left(500-5000 \mathrm{~s}^{-1}\right)^{33}$, Smith et al. ${ }^{23}$ indicated that xanthan was more resistant to the effects of cations in solution than other polymers. By systematically evaluating the effects of ionic strength on solution rheology, Zhong et al. ${ }^{18}$ showed that increasing $\mathrm{Na}^{+}$and $\mathrm{Ca}^{2+}$ ions $(0-$ $50 \mathrm{mg} \mathrm{L}^{-1}$ ) decreased the viscosity of xanthan, but at high xanthan concentrations, the opposite trend was observed. In an earlier study, Zhong et al. ${ }^{16}$ also reported a slight increase in viscosity across shear rates between 0.1 and $100 \mathrm{~s}^{-1}$ when 600 


\begin{tabular}{|c|c|c|c|c|c|c|}
\hline \multirow[b]{2}{*}{ Treatment } & \multicolumn{6}{|c|}{ Pore Volume } \\
\hline & 0.27 & 0.54 & 0.81 & 1.08 & 1.53 & 1.98 \\
\hline \multicolumn{7}{|l|}{$\begin{array}{c}\text { Exp. 1A } \\
\text { Red Dye-CaCl } \\
\text { Xanthan (500 mg L-1) }\end{array}$} \\
\hline \multicolumn{7}{|l|}{2.0 Pore Volumes } \\
\hline \multicolumn{7}{|l|}{$\begin{array}{c}\text { Exp. 1B } \\
\mathrm{MnO}_{4}-\left(4000 \mathrm{mg} \mathrm{L}^{-1}\right)\end{array}$} \\
\hline \multicolumn{7}{|l|}{ 2.0 Pore Volumes } \\
\hline \multicolumn{7}{|l|}{$\begin{array}{c}\text { Exp. 1C } \\
\mathrm{MnO}_{4}\left(4000 \mathrm{mg} \mathrm{L}^{-1}\right)\end{array}$} \\
\hline \multicolumn{7}{|l|}{0.5 Pore Volumes } \\
\hline \multirow{2}{*}{\multicolumn{7}{|c|}{$\begin{array}{c}\text { Exp. 1D } \\
\mathrm{MnO}_{4}\left(4000 \mathrm{mg} \mathrm{L}^{-1}\right) \\
\text { Xanthan }^{2}\left(250 \mathrm{mg} \mathrm{L}^{-1}\right) \\
0.5 \text { Pore Volumes }\end{array}$}} \\
\hline & & & & & & \\
\hline \multirow{4}{*}{\multicolumn{7}{|c|}{ 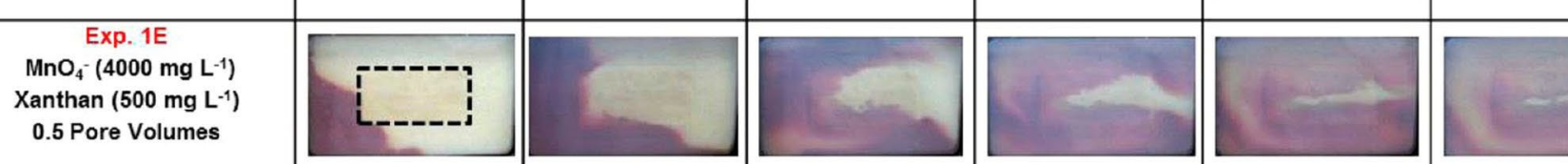 }} \\
\hline & & & & & & \\
\hline & & & & & & \\
\hline & & & & & & \\
\hline \multirow{2}{*}{\multicolumn{7}{|c|}{$\begin{array}{c}\text { Exp. 1F } \\
\mathrm{MnO}_{4}^{-}\left(4000 \mathrm{mg} \mathrm{L}^{-1}\right)\end{array}$}} \\
\hline & & & & & & \\
\hline $\begin{array}{l}\text { Xanthan ( }\left(1000 \mathrm{mg}^{-1}\right) \\
0.5 \text { Pore Volumes }\end{array}$ & & & & & & \\
\hline & & & & & & \\
\hline
\end{tabular}

Figure 2. Photographs of temporal changes in $2 \mathrm{D}$ tank coverage by conventional flooding (Exps. 1A-1F).

mg L ${ }^{-1}$ xanthan was mixed with $6000 \mathrm{mg} \mathrm{Na}^{+} \mathrm{L}^{-1}$ versus 400 $\mathrm{mg} \mathrm{Na} \mathrm{L}^{-1}$. While the associated cation from the permanganate salt may be responsible for increasing the viscosity of the xanthan solutions (Figure 1B), the fact that permanganate reacts with xanthan to some degree means that the intermolecular bonding between the $\mathrm{MnO}_{4}^{-}$and xanthan as well as the products produced (e.g., $\mathrm{MnO}_{2}$ ) could also have contributed.

We also quantified the temporal stability of the xanthan$\mathrm{MnO}_{4}{ }^{-}$solutions and found that the viscosities of the xanthan$\mathrm{MnO}_{4}^{-}$solutions significantly declined with holding times $>12$ $\mathrm{h}$ and that this instability consequently inhibited "aged" xanthan- $\mathrm{MnO}_{4}{ }^{-}$solutions from penetrating the LPZ during transport. A detailed description of experiments that support this conclusion is provided in the Supporting Information section (Figures SI-2-SI-5).

$\mathrm{MnO}_{4}{ }^{-}$Penetration into LPZ and ${ }^{14} \mathrm{C}$-TCE Mass Recovery Using Conventional Flooding. Multiple transport experiments were performed and photographed to systematically evaluate the ability of xanthan to increase the penetration of permanganate into the low permeable zone (Figure 2). Variables adjusted included the initial and secondary flooding solutions, xanthan concentrations, and pore volumes of initial floods (Table S2). Sweeping efficiency 16, 33 was qualitatively defined as the percentage of LPZ that was visibly covered by the flooding solution as a function of pore volume (method details provided in the SI). A graph displaying sweeping efficiencies of the various treatments is provided in the Supporting Information (Figure SI-6). Initial transport experiments injected 2 pore volumes of either xanthan $\left(500 \mathrm{mg} \mathrm{L}^{-1}\right)$ or $\mathrm{MnO}_{4}^{-}$(Exps. 1A-1B). Using xanthan alone, the injectate front moved nearly perpendicular to the direction of flow (i.e., $\sim 90^{\circ}$ tilt angle) and effectively swept through the LPZ (Figure 2, Exp. 1A). Previous publications have reported similar observations. ${ }^{13-17}$ Using $\mathrm{MnO}_{4}{ }^{-}$alone, considerable bypass around the LPZ was observed, even after injecting 2 pore volumes of $\mathrm{MnO}_{4}{ }^{-}$into the 2D tank (Figure 2, Exp. 1B).

To verify that the visual coverage of the LPZ by permanganate corresponded with actual TCE oxidation, we selectively sampled the pore water in and around the LPZ during transport (Exp. 1B). We sampled the transmissive zone up gradient and down gradient of the LPZ as well as inside the LPZ (Figure 3). Results confirmed that the two sampling points not visually covered by $\mathrm{MnO}_{4}^{-}$had the highest ${ }^{14} \mathrm{C}$-TCE activity remaining in solution, with one sampling point in the center of the LPZ still registering the starting fluid concentration (i.e., $\left.C / C_{o}=1\right)$. These results confirm that the five pore volumes of dissolved TCE initially used to condition the 2D tank (prior to injecting the treatments) dispersed TCE throughout the LPZ and that bypass of the LPZ by the migrating $\mathrm{MnO}_{4}^{-}$left some of the LPZ pore water at the initial starting concentration.

When the volume of the initial flood was reduced to 0.5 PV and followed by a secondary flush of 1.5 pore volumes of $\mathrm{CaCl}_{2}$, we again observed that injecting $\mathrm{MnO}_{4}^{-}$alone (Exp. $1 \mathrm{C}$ ) covered mainly the transmissive zone and only penetrated $50 \%$ of the LPZ (Figure 2). When xanthan was included in the initial flush (Exps. 1D-1F), sweeping efficiencies increased to $>80 \%$, with the $500 \mathrm{mg} \mathrm{L}^{-1}$ xanthan concentration yielding the highest sweeping efficiency (92\%, Figure SI-6). This indicates the xanthan solution provided shear thinning to the oxidant flood and allowed more $\mathrm{MnO}_{4}{ }^{-}$penetration into the LPZ. 


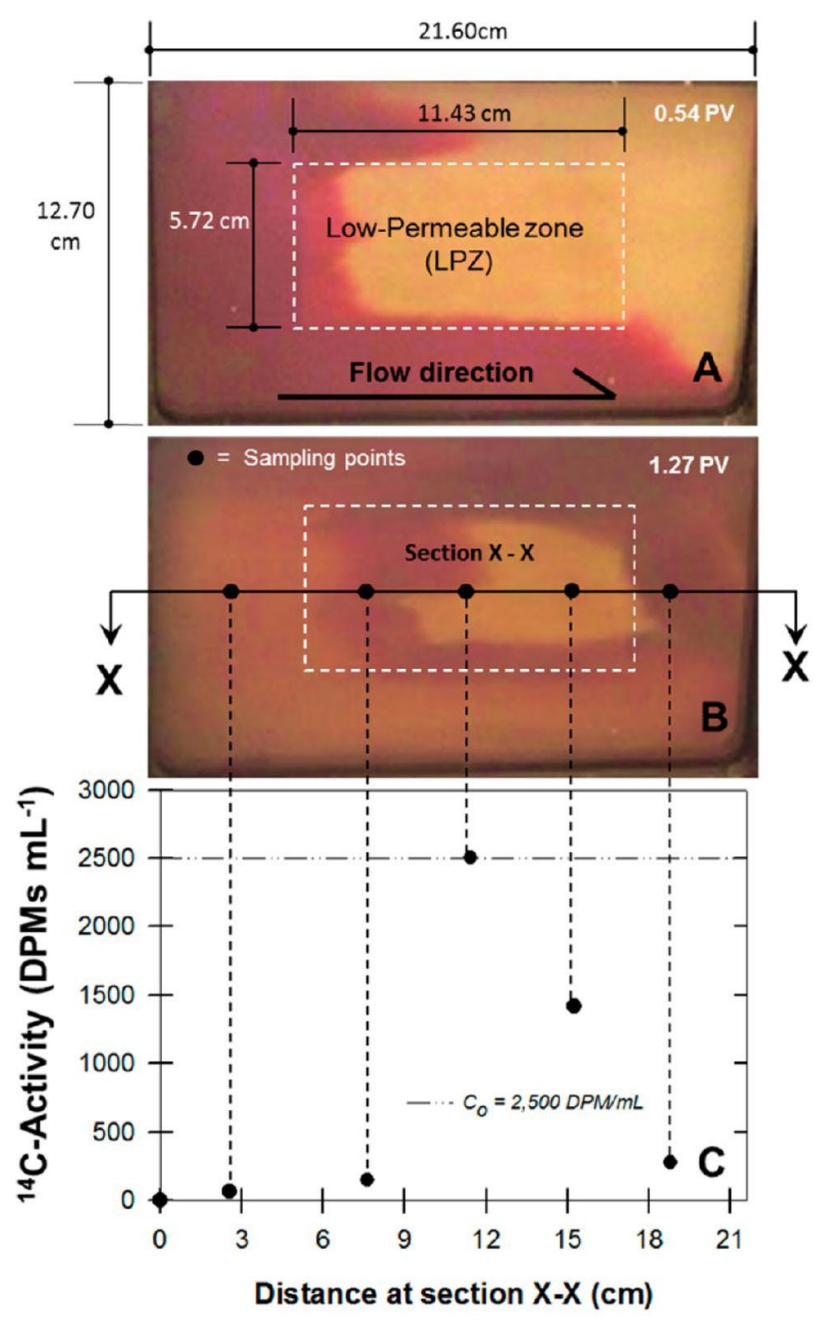

Figure 3. The relationship between visual coverage of LPZ by permanganate and ${ }^{14} \mathrm{C}$-activity.

Although xanthan improved the sweeping efficiency of the $\mathrm{MnO}_{4}^{-}$, the displacing front was not perpendicular to flow when $\mathrm{MnO}_{4}{ }^{-}$was included. Rather, gravity under ride was observed with all $\mathrm{MnO}_{4}^{-}$-xanthan floods (Exps. 1B-1F) and resulted from density differences between the flooding solution and resident fluid (i.e., dissolve phase TCE). Schincariol and Schwartz ${ }^{34}$ observed unstable flow displacements when density differences were $\geq 0.8 \mathrm{~kg} \mathrm{~m}^{-3}$. The solution densities of the various $\mathrm{MnO}_{4}^{-}$-xanthan concentrations used in our experiments differed by up to $5 \mathrm{~kg} \mathrm{~m}^{-3}$, and, as expected, increasing $\mathrm{MnO}_{4}^{-}$concentrations increased solution density while adding xanthan decreased solution density (see Figure SI-7). This counteracting effect resulted in the ratio of $4000 \mathrm{mg} \mathrm{L}^{-1} \mathrm{MnO}_{4}^{-}$ to $500 \mathrm{mg} \mathrm{L}^{-1}$ xanthan having a solution density very similar to the control (i.e., no added amendments, Figure SI-7).

Sweeping Efficiency and ${ }^{14} \mathrm{C}$-TCE Mass Recovery during Multi-Step Flooding. Additional transport experiments used a series of flooding solutions to treat dissolved-phase TCE and calculate mass recovery. This multiple-step flooding consisted of three stages (Table S2). The first step introduced a smaller pore volume of injectate (0.25 PV) in an attempt to get closer to realistic oxidant volumes used in field applications. The second step followed the initial flood with background solution for 2.75 PV. Then, to ensure that all untreated TCE was

\section{A. Sweeping Efficiency of LPZ}

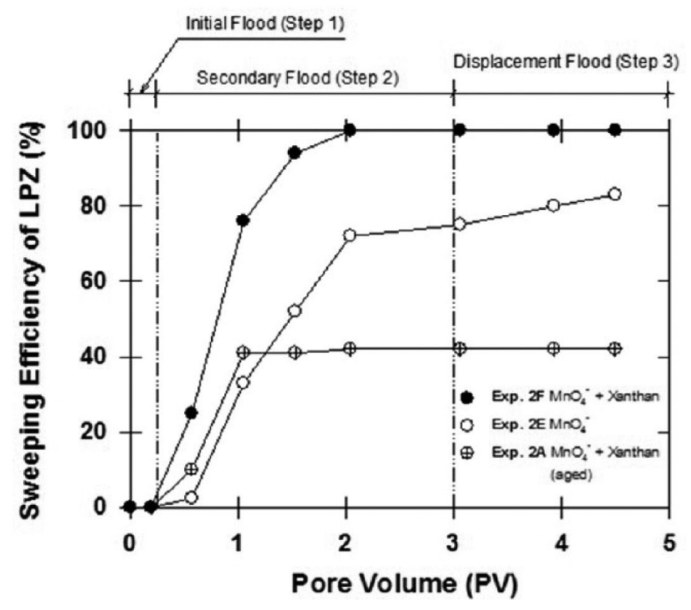

B. Photographs of LPZs

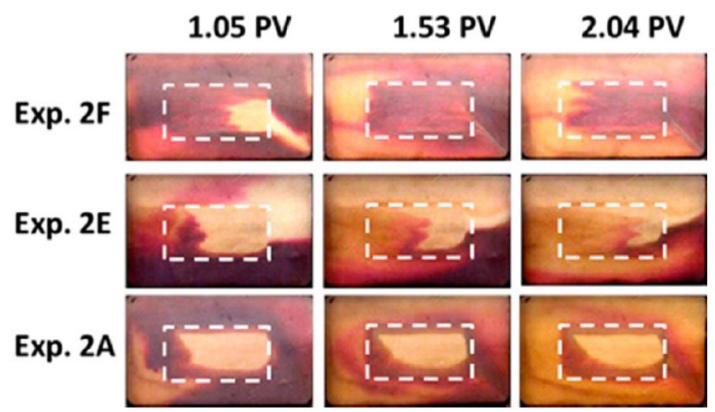

Figure 4. A. Sweeping efficiencies of multistep flooding experiments (Exps. 2A, 2E, 2F). B. Photographs of LPZ coverage for Exps. 2A, 2E, $2 \mathrm{~F}$ at $1.05,1.53$, and $2.04 \mathrm{PV}$.

displaced from the 2D tank and could be used to determine mass balance calculations, the third step was to inject $1.5 \mathrm{PV}$ of xanthan solution to displace fluid from the tank (i.e., mobilization flood).

The delivery of oxidant into the LPZ can be observed by the calculated sweeping efficiencies (Figure 4, Figure SI-6) and through time-lapse photography (Figure 4, Figure SI-8). When $\mathrm{MnO}_{4}{ }^{-}$was part of the initial flood, significant differences between treatments were observed. In Experiment 2A, the xanthan $\mathrm{MnO}_{4}^{-}$mixture was stirred for $24 \mathrm{~h}$ prior to use. Because xanthan started to lose its viscosity, most of the oxidant stayed in the transmissive zone and sweeping efficiency only reached $40 \%$ (Figure 4 ). When $\mathrm{MnO}_{4}^{-}$was injected by itself, the sweeping efficiency was $75 \%$ at $3 \mathrm{PV}$. However, when xanthan was also included (Exp. 2F), the sweeping efficiency reached $100 \%$ after $\sim 2.1$ PV. Finally, a comparison of displacing fronts, with and without xanthan, shows that gravity under ride was observed with $\mathrm{MnO}_{4}^{-}$alone (Exp. 2E, Figure SI$8)$, but a more perpendicular front was observed when the xanthan was included (Exp. 2F, Figure SI-8). As mentioned earlier, the 4000:500 $\mathrm{MnO}_{4}^{-}$:xanthan ratio had the smallest difference in solution density to the control (Figure SI-7).

Displacing Untreated Dissolved-Phase TCE with Xanthan. Because the $2 \mathrm{D}$ tank was saturated with ${ }^{14} \mathrm{C}$-labeled, dissolve-phase TCE, flooding the system allowed us to monitor temporal changes in ${ }^{14} \mathrm{C}$-activity in the effluent. By using xanthan in the displacement flood (Step 3), we supplanted any ${ }^{14} \mathrm{C}$ that was not oxidized or displaced by the initial or secondary 


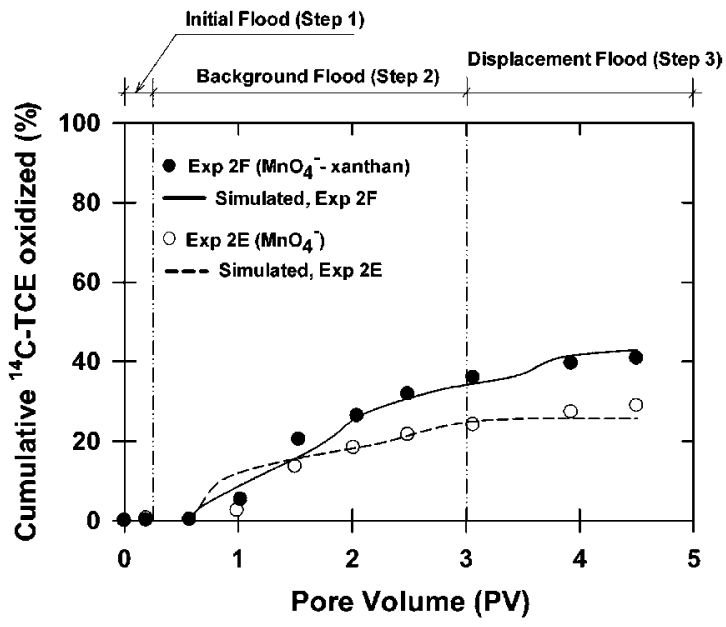

Figure 5. Simulated and measured cumulative ${ }^{14} \mathrm{C}$-TCE oxidized by oxidant and oxidant-polymer flushing.

floods (Steps 1 and 2). Given that rebound or back diffusion is attributable to the release of chlorinated solvents from low permeable zones back into transmissive zones, once the transmissive zones have been treated, the use of xanthan as a displacement flood provided a means of showing which treatment could be potentially vulnerable to rebound. Plotting ${ }^{14} \mathrm{C}$-activity in the effluent as a function of pore volume (Figure SI-9) revealed that some treatments produced a small but separate ${ }^{14} \mathrm{C}$-breakthrough curve (BTC) during the displacement flood. The initial flood treatments that produced these secondary BTCs were the control (Exp. 2C), $\mathrm{MnO}_{4}^{-}$alone (Exp. 2E), and the $\mathrm{MnO}_{4}^{-}{ }^{-}$-xanthan solution that was aged overnight (Exp. 2A). By comparison treatments where xanthan was present in the initial flood (Exps. 2D and 2F) showed no evidence of a secondary BTC. These results only confirm what was visually observed. Namely, those treatments that resulted in incomplete coverage of the LPZ (Figure SI-8) and, hence, had low sweeping efficiencies (Figure 4, Figure SI-6) were the ones that have the potential to produce rebound.

${ }^{14} \mathrm{C}$-TCE Oxidized During Transport: Experimental and Simulated Results. Given that the use of xanthan in the initial flood improved the sweeping efficiency of $\mathrm{MnO}_{4}^{-}$into the LPZ and reduced the mass of TCE left in the LPZ, the final question remaining was how much did xanthan improve the overall oxidation of TCE during transport. Given that the TCE is pushed out as the oxidant is pumped in, it is often difficult to quantify treatment differences in short, finite-length tanks. Nonetheless, because our sampling protocol allowed us to differentiate the effluent into ${ }^{14} \mathrm{C}$-TCE, ${ }^{14} \mathrm{C}$-degradation products, and ${ }^{14} \mathrm{CO}_{2}$, the amount of cumulative ${ }^{14} \mathrm{C}$-TCE oxidized $\left({ }^{14} \mathrm{C}\right.$-products and $\left.{ }^{14} \mathrm{CO}_{2}\right)$ could be calculated (Figure 5). Results show that the majority of oxidized products started to elude from the 2D tank after $\sim 1$ PV and likely included oxidized products produced in and around the LPZ.

When only $\mathrm{MnO}_{4}^{-}$was used in the initial flush (Exp. 2E), the percent TCE oxidized after 4.5 pore volumes was $28.9 \%$ and represents TCE oxidized in the transmissive zone and a portion of the LPZ. When xanthan was mixed with $\mathrm{MnO}_{4}^{-}$ and injected immediately (Exp. $2 \mathrm{~F}$ ), the amount of ${ }^{14} \mathrm{C}-\mathrm{TCE}$ oxidized increased to $40.8 \%$. This higher rate of oxidation obviously resulted from a greater percentage of the LPZ being treated $(100 \%$ sweeping efficiency at $2 \mathrm{PV})$ but also by the

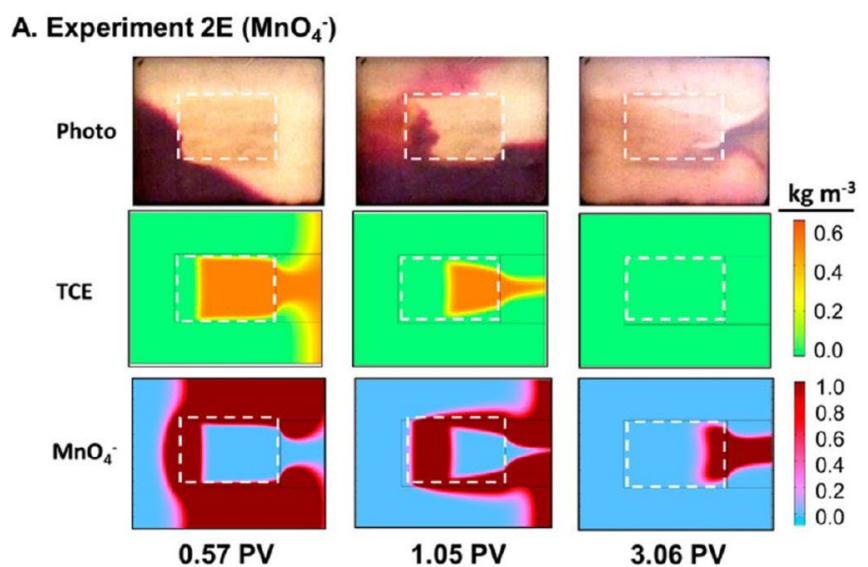

B. Experiment $2 \mathrm{~F}\left(\mathrm{MnO}_{4}{ }^{-}+\right.$Xanthan $)$

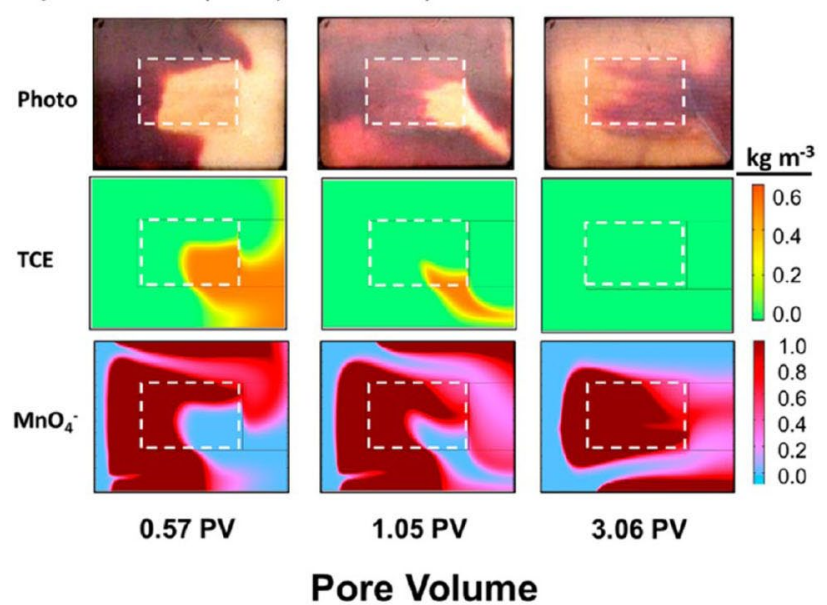

Figure 6. Observed and simulated transport of permanganate and TCE following permanganate injections without xanthan $(A)$ and with xanthan $(B)$ as the initial floods for transport experiments $2 \mathrm{E}$ and $2 \mathrm{~F}$.

fact that the $\mathrm{MnO}_{4}{ }^{-}$traversed faster in the transmissive zone on both sides of the LPZ and engulfed the LPZ after approximately $1 \mathrm{PV}$ (see photos in Figure 6). This means $\mathrm{MnO}_{4}{ }^{-}$was present at the backside or down gradient of the LPZ when the dissolved-phase TCE was being pushed out of the LPZ.

To date, there have only been a few attempts to numerically simulate polymer flow into LPZs. Zhong et al. ${ }^{16}$ successfully modified the Subsurface Transport Over Multiple Phases (STOMP) simulator to predict the flow of xanthan into low permeable zones. Recently, Silva et al. ${ }^{19}, 20$ advanced these modeling efforts by using the University of Texas Chemical Composition (UTCHEM) simulator, which accounts for shearthinning rheology and also includes polymer retention and acceleration parameters. To our knowledge, the coupling of non-Newtonian flow with reactive transport has not been undertaken. By taking such an approach and coupling a reactive transport model with the Brinkman equation (Equations 1-8), we were able to simulate the amount of ${ }^{14} \mathrm{C}$-TCE oxidized during transport, with and without xanthan (Figure 5).

In these simulations, the permeability of the LPZ and the reaction rate in the transmissive zone were treated as the fitting parameters and were obtained by trial and error (Table S3). The permeability of the low permeable zone was adjusted by comparing the simulated polymer movement in the LPZ with the time-lapse photos (Figure 6). The reaction rate 
in the transmissive zone was adjusted by comparing the simulated mass of TCE oxidized with measured values. Sensitivity analysis of Experiments $2 \mathrm{E}$ and $2 \mathrm{~F}$ found that the product of the reaction rate constants $\left(k_{\mathrm{TZ}}, k_{\mathrm{LPZ}}, \mathrm{m}^{3} / \mathrm{kg} \cdot \mathrm{s}\right)$ and Peclet numbers $\left(P e_{\mathrm{TZ}}, P e_{\mathrm{LPZ}}\right)$ for the transmissive zone (TZ) and the LPZ were constant:

$$
k_{\mathrm{TZ}} \times P e_{\mathrm{TZ}}=k_{\mathrm{LPZ}} \times P e_{\mathrm{LPZ}}
$$

The Peclet number in the transimissve zone $\left(P e_{\mathrm{TZ}}\right)$ and $\mathrm{LPZ}$ $\left(P e_{\text {LPZ }}\right)$ were estimated as $\left(v d_{50}\right) / D^{*}$, where $v$ is the corresponding average fluid velocities of the domain during $\mathrm{MnO}_{4}^{-}$injection, $d_{50}$ is the estimated median grain sizes (Table S3), and $D^{*}$ is the TCE diffusion coefficient. Equation 9 was used to estimate $k_{\mathrm{TZ}}$. When $\mathrm{MnO}_{4}{ }^{-}$was injected alone (Exp. 2E), our simulated transport of permanganate did not mimic the gravity under ride we observed in the transmissive zone because density was not accounted for in the model. However, the model was able to approximate the temporal sweeping efficiency of the LPZ (Figure 6A). When $\mathrm{MnO}_{4}^{-}$was paired with xanthan, the model closely mimicked $\mathrm{MnO}_{4}^{-}$movement by engulfing the LPZ and leaving TCE in the bottom right-hand corner of the LPZ as the last area to be swept by the migrating permanganate (Figure 6B). This simulated cross-flow was created by the pressure and viscosity distribution generated in the transmissive zone and the LPZ, which resulted from the shear-thinning rheology of including xanthan with $\mathrm{MnO}_{4}{ }^{-}$in the initial flood. Additional sensitivity analyses of the validated numerical model showed that xanthan still improved the oxidation of TCE in the LPZ even when the permeability contrast between the transmissive and LPZ zones was increased 10 -fold. We also found that reducing the flow rates would lead to higher removal rates, due to longer reaction times.

Although a number of physical and biological factors must first be considered before using xanthan under field conditions, ${ }^{18}$ our experimental and simulated results support combining xanthan with permanganate as a means of increasing the mass of dissolved-phase TCE oxidized in low permeable zones and reducing the potential for rebound.

\section{Supporting Information}

Details of experimental procedures and further explanation of results are presented following the References.

\section{References}

1. Stroo, H. F., Unger, M., Ward, C. H., Kavanaugh, M. C., Vogel, C., Leeson, A., Marqusee, J. A., Smith, B. P. Remediating chlorinated solvent source zones. Environ. Sci. Technol. 2003, 37, 224A-230A

2. Mackay, D. M., Cherry, J. A. Groundwater contamination: Pump-and-treat remediation. Environ. Sci. Technol. 1989, 23, 630-636

3. Travis, C., Doty, C. ES\&T Views: Can contaminated aquifers at superfund sites be remediated? Environ. Sci. Technol. 1990, 24, 1464-1466

4. Stroo, H. F., Leeson, A., Marqusee, J. A., Johnson, P. C., Ward, C. H., Kavanaugh, M. C., Sale, T. C., Newell, C. J., Pennell, K. D., Lebrón, C. A., Unger, M. Chlorinated eth- ene source remediation: Lessons learned. Environ. Sci. Technol. 2012, 46, 6438-6447

5. Liu, C. X., Ball, W. P. Back diffusion of chlorinated solvent contaminants from a natural aquitard to a remediated aquifer under well-controlled field conditions: Predictions and measurements. Ground Water 2002, 40, 175-184

6. Mundle, K., Reynolds, D. A., West, M. R., Kueper, B. H. Concentration rebound following in situ chemical oxidation in fractured clay. Ground Water 2007, 45, 692-702

7. Goldstein, K. J., Vitolins, A. R., Navon, D., Parker, B. L., Chapman, S. W., Anderson, G. A. Characterization and pilot-scale studies for chemical oxidation remediation of fractured shale. Remediation 2004, 14, 19-37

8. Marvin, B. K., Chambers, J., Leavitt, A., Schreier, C. G. Chemical and engineering challenges to in situ permanganate remediation. In Remediation of Chlorinated and Recalcitrant Compounds, Gavaskar, A. R., Chen, A. S. C., eds., Proceedings of the Third International Conference on Remediation of Chlorinated and Recalcitrant Compounds, Battelle Press: Columbus, OH, 2002.

9. McGuire, T. M., McDade, J. M., Newell, C. J. Performance of DNAPL source depletion technologies at 59 chlorinated solvent-impacted sites. Ground Water Monit. Rem. 2006, 26, 73-84

10. Sale, T., Newell, C., Stroo, H., Hinchee, R., Johnson, P. Frequently asked questions regarding the management of chlorinated solvents in soils and groundwater. Environmental Security Testing and Certification Program (ESTCP): Washington, DC, 2007.

11. Krembs, F. J., Siegrist, R. L., Crimi, M. L., Furrer, R. F., Petri, B. G. ISCO for groundwater remediation: Analysis of field applications and performance. Ground Water Monit. Rem. 2010, 30, 42-53

12. Siegrist, R. L., Crimi, M., Simpkin, T. J., Brown, R. A., Unger, M. ISCO status and future directions. In In Situ Chemical Oxidation for Groundwater Remediation, Siegrist, R. L., Crimi, M., Simpkin, T. J., eds., Springer Publishing: New York, NY, 2011, pp 535-546.

13. Martel, K. E., Martel, R., Lefebvre, R., Gelinas, P. J. Laboratory study of polymer solutions used for mobility control during in situ NAPL recovery. Ground Water Monit. Rem. 1998, 18, 103-113

14. Martel, R., Hebert, A., Lefebvre, R., Gelinas, P., Gabriel, U. Displacement and sweep efficiencies in a DNAPL recovery test using micellar and polymer solutions injected in a fivespot pattern. J. Contam. Hydrol. 2004, 75, 1-29

15. Robert, T., Martel, R., Conrad, S. H., Lefebvre, R., Gabriel, U. Visualization of TCE recovery mechanisms using surfactant-polymer solutions in a two-dimensional heterogeneous sand model. J. Contam. Hydrol. 2006, 86, 3-31

16. Zhong, L., Oostrom, M., Wietsma, T. W., Covert, M. A. Enhanced remedial amendment delivery through fluid viscosity modifications: Experiments and numerical simulations. J. Contam. Hydrol. 2008, 101, 29-41

17. Zhong, L., Szecsody, J., Oostrom, M., Truex, M., Shen, X., $\mathrm{Li}, \mathrm{X}$. Enhanced remedial amendment delivery to subsurface using shear thinning fluid and aqueous foam. J. Hazard. Mater. 2011, 191, 249-257 
18. Zhong, L., Oostrom, M., Truex, M. J., Vermeul, V. R., Szecsody, J. E. Rheological behavior of xanthan gum solution related to shear thinning fluid delivery for subsurface remediation. J. Hazard. Mater. 2013, 244-245, 160-170

19. Silva, J. A. K., Smith, M. M., Munakata-Marr, J., McCray, J. E. The effect of system variables on in situ sweep-efficiency improvements via viscosity modification. J. Contam. Hydrol. 2012, 136, 117-130

20. Silva, J. A. K., Liberatore, M., McCray, J. E. Characterization of bulk fluid and transport properties for simulating polymer-improved aquifer remediation. J. Environ. Eng. 2013, Feb, 149-159

21. Baijal, S. K. Flow Behavior of Polymers in Porous Media, Pennwell Publishing Company: Tulsa, OK, 1982.

22. Lake, L. W. Enhanced Oil Recovery, Prentice-Hall, Inc.: Englewood Cliffs, NJ, 1989.

23. Smith, M. M., Silva, J. A. K., Munakata-Marr, J., McCray, J. E. Compatibility of polymers and chemical oxidants for enhanced groundwater remediation. Environ. Sci. Technol. 2008, 42, 9296-9301

24. McCray, J. E., Munakata-Marr, J., Silva, J. A. K., Davenport, S., Smith, M. M. Multi-scale experiments to evaluate mobility control methods for enhancing the sweep efficiency of injected subsurface. Department of Defense Strategic Environmental Research and Development Program (SERDP) project. No. ER-1486, 2010.

25. Littmann, W. Polymer Flooding, Elsevier Science Publishers: New York, NY, 1988.

26. Huang, K. C., Hoag, G. E., Chheda, P., Woody, B. A., Dobbs, G. M. Chemical oxidation of trichloroethylene with potassium permanganate in a porous medium. Adv. Environ. Res. 2002, 7, 217-229
27. Kriegman-King, M. R., Reinhard, M. Transformation of carbon tetrachloride in the presence of sulfide, biotite, and vermiculite. Environ. Sci. Technol. 1992, 26, 2198-2206

28. Brinkman, H. A calculation of the viscous force exerted by a flowing fluid on a dense swarm of particles. Appl. Sci. Res. 1949, 1, 27-34

29. Hamdan, M. H., Kamel, M. T., Siyyam, H. I. A permeability function for Brinkman's equation. Proceedings of the $11^{\text {th }}$ WSEAS international conference on Mathematical methods, computational techniques and intelligent systems, 2009, pp 198-205.

30. Uscilowska, A. Non-newtonian fluid flow in a porous media. J. Mech. Mater. Struct. 2008, 3, 1151-1159

31. Lopez, P. H., Valvatne, M. J., Blunt, M. J. Predictive network modeling of single-phase non-Newtonian flow in porous media. J. Colloid Interface Sci. 2003, 264, 256-265

32. Chen, C. S. H., Sheppard, E. W. Conformation and shear stability of xanthan gum in solution. Polym. Eng. Sci. 1980, 20, 512-516

33. Neil, J. D., Chang, H. L., Geffen, T. M. Waterflooding and improved waterflooding. In Improved Oil Recovery, Bond, D. C., Hocott, C. R., Poettmann, F. H., eds., Interstate Oil Compact Commission: Oklahoma City, OK, 1983.

34. Schincariol, R. A., Schwartz, F. W. An experimental investigation of variable density flow and mixing in homogeneous and heterogeneous media. Water Resour. Res. 1990, 26, 2317-2329 
2
Improving the sweeping efficiency of permanganate into low permeable zones to treat TCE: Experimental results and model development

CHANAT CHOKEJAROENRAT ${ }^{\dagger, \ddagger}$, NEGIN KANANIZADEH ${ }^{\dagger}$, CHAINARONG SAKULTHAEW ${ }^{\S, \mp}$, STEVE COMFORT ${ }^{\S,}{ }^{*}$, AND YUSONG LI $^{\dagger}$

Department of Civil Engineering, University of Nebraska-Lincoln, Lincoln, NE 685880531, School of Environmental Engineering, Institute of Engineering, Suranaree University of Technology, Nakorn Ratchasima, Thailand 30000, School of Natural Resources, University of Nebraska-Lincoln, Lincoln, NE 68583-0915, Department of Veterinary Technology, Faculty of Veterinary Technology, Kasetsart University, Bangkok, Thailand 10900,

${ }^{\dagger}$ Department of Civil Engineering, University of Nebraska-Lincoln

$\ddagger$ Suranaree University of Technology, Nakorn Ratchasima, Thailand

$\S$ School of Natural Resources, University of Nebraska-Lincoln

${ }^{\mp}$ Kasetsart University, Bangkok, Thailand

Supporting Information for Chokejaroenrat et al./Journal submission

Page |S1 
Contents

MATERIALS AND METHODS

\section{REFERENCES}

RESULTS AND DISCUSSION

Temporal Stability of $\mathrm{MnO}_{4}{ }^{-}$-Xanthan Solutions

TABLES

FIGURES

\section{ACKNOWLEDGMENTS}

Funding was provided in part by the EPA Region 7, Project ER-0635. This paper is a contribution of Agricultural Research Division Project NEB-38-071. The authors gratefully thank Dr. William H. Velander and Dr. Jennifer Calcaterra, (Department of Chemical and Biomolecular Engineering, University of Nebraska-Lincoln) for use of their viscometer. 
MATERIALS AND METHODS

Chemicals and Soils. Trichloroethene (TCE; $\mathrm{C}_{2} \mathrm{HCl}_{3} ; \mathrm{ACS}$ reagent, $\geq 99.5 \%$ ) and sodium permanganate $\left(\mathrm{NaMnO}_{4}, 40 \%\right.$ by weight) were obtained from Sigma-Aldrich (St. Louis, MO). Xanthan gum (CAS-11138-66-2) (Sigma-Aldrich), nitric acid (J.T. Baker, Phillipsburgh, NJ), and sodium hydroxide (Fisher Scientific, Pittsburgh, PA) were used as purchased. Physiochemical properties of the main chemicals used in the transport experiments (TCE, xanthan, and $\mathrm{MnO}_{4}^{-}$) are provided (Table S1).

Soils used in transport experiments were chosen to create a transmissive zone and a low permeable zone (LPZ). The transmissive zone was packed with commercial silica sand (Accusand 20/30, Le Sueur, MN) while the low permeability zone was fabricated by mixing a silty clay loam soil with a silica sand (Accusand 40/50) in a 1:16 $(w / w)$ ratio. The silty clay loam was used to increase mass of TCE retained by the LPZ (Sale et al., 2008). This silty clay loam was obtained from a loess deposit $\sim 6.1 \mathrm{~m}$ below ground surface on the University of Nebraska campus (Lincoln, NE).

Viscosity-Shear Rate Relationship. The effects of xanthan and $\mathrm{MnO}_{4}^{-}$ concentrations on the viscosity-shear rate relationship were quantified. This was accomplished by preparing varying concentrations of xanthan and $\mathrm{MnO}_{4}^{-}$and measuring viscosities across varying shear rates. To prepare the xanthan stock solution, we slowly added xanthan powder to $\mathrm{H}_{2} \mathrm{O}$ while stirring to avoid powder formation of the glass wall. Because xanthan preparation can directly affect the solution viscosity (Chen and Sheppard, 1979), once mixed, the xanthan stock solution $\left(2 \mathrm{~g} \mathrm{~L}^{-1}\right)$ was continuously mixed on a magnetic stirrer for $90 \mathrm{~min}$ at room temperature $\left(25^{\circ} \mathrm{C}\right)$ and used within $2 \mathrm{~h}$, unless stated otherwise.

To quantify how solution viscosity changed with varying xanthan concentrations, we diluted the xanthan stock solution to $125,250,500,750$, and $1000 \mathrm{mg} \mathrm{L}^{-1}$. Solution viscosity was then monitored with a cone/plate DV-II + Pro Brookfield Viscometer 
(Brookfield Engineering Laboratories, Middleboro, MA) over shear rates ranging from 0.1 to $400 \mathrm{~s}^{-1}$. This range of shear rate would adequately cover a variety of aquifer matrices and conditions.

To quantify the effects of $\mathrm{MnO}_{4}^{-}$concentrations on the viscosity of xanthan, we prepared xanthan solutions of 500,1000 , and $1250 \mathrm{mg} \mathrm{L}^{-1}$ and spiked each with $\mathrm{NaMnO}_{4}$ at 1250, 2500,5000, 10000, and $12500 \mathrm{mg} \mathrm{MnO}_{4}^{-} \mathrm{L}^{-1}$. Once the xanthan$\mathrm{MnO}_{4}^{-}$solutions were completely mixed, the viscosity-shear rate relationship was measured.

Temporal Stability of Xanthan- $\mathrm{MnO}_{4}{ }^{-}$. To quantify the temporal stability of the xanthan- $\mathrm{MnO}_{4}{ }^{-}$solutions, we measured viscosity-shear rate values periodically over $9 \mathrm{~d}$. In this experiment, a $500 \mathrm{mg} \mathrm{L}^{-1}$ xanthan solution was spiked with $\mathrm{NaMnO}_{4}$ at an initial concentration of 2500 and $10000 \mathrm{mg} \mathrm{L}^{-1}$. Each flask was then covered with paraffin film and aluminum foil to prevent $\mathrm{MnO}_{4}{ }^{-}$photodegradation, and agitated on an orbital shaker at ambient temperature $\left(25^{\circ} \mathrm{C}\right)$ until analysis. Sampling occurred at $0,0.25,0.75,1,3,5$, 7, and $9 \mathrm{~d}$. For each sampling time, we measured viscosity, as previously described, and $\mathrm{MnO}_{4}^{-}$concentrations $(\mathrm{n}=3) . \mathrm{MnO}_{4}^{-}$was measured with a $\mathrm{HACH}$ Spectrophotometer DR2800 (HACH Company, Loveland, CO) at a wavelength of 525 $\mathrm{nm}$. Samples were diluted with water in $20-\mathrm{mL}$ vials and filtered with $0.45 \mu \mathrm{m}$ glass wool membrane prior to analysis to avoid any colloidal interference from $\mathrm{MnO}_{2}$ (Chokejaroenrat et al., 2011), and to remove any possible gel formations (Zhong et al., 2008).

2D-Tank. All transport experiments were conducted in the specifically designed rectangular anodized aluminum tank (2D-Tank) consisting of three chambers. The main chamber $\left(1061 \mathrm{~cm}^{3}\right)$ housed the soil and had internal dimensions of $21.6 \mathrm{~cm}$ (length) by $12.7 \mathrm{~cm}$ (height) by $5.1 \mathrm{~cm}$ (width) (Fig. SI-1). The other two chambers were up gradient (inlet) and down gradient (outlet) of the main chamber. The inlet chamber was packed 
with 4-mm diam glass beads (Fisher Scientific, Pittsburgh, PA) to promote mixing. Titanium mesh was also used in the inlet and main chambers to prevent clogging of the array of tank openings between chambers. The outlet chamber $\left(49.9 \mathrm{~cm}^{3}\right)$ collected the effluent from the main chamber and had three exit ports (top, middle, and bottom), which were used for sampling. The front and back of the 2D-tank consisted of glass plates that allowed us to visually observe fluid flow in the transmissive and low permeable zones. All joints of the 2D-Tank assembly were secured with PTFE o-rings that fit closely inside the tank to prevent any leakage. The influent and effluent connections were constructed out of 316 stainless steel tubing (3.18-mm dia.) equipped with stainless steel 3-way Swagelock valves. Liquid flow was controlled with an HPLC pump (Shimadzu Scientific Instruments, Columbia, MD) that provided a constant flow rate. All additional tubing was either stainless steel or PTFE (Teflon) to minimize TCE adsorption.

Establishing Transmissive and Low Permeable Zones in the 2D Tank. The 2D tank was hand packed with a rigorous set of steps and procedures to ensure uniformity between experiments. This involved using the same soil weights and template tools to produce a low permeable zone surrounded by a transmissive zone. In brief, the steps used to pack the 2D tank were as follows: (1) the tank was divided into 7 layers before placing the transmissive sand into the tank; (2) after adding each layer of soil, we dry-packed the tank by gently packing with a specifically designed rubber hammer and shaking the tank horizontally at each packing level, (3) when the tank was packed to the height of the LPZ base, we marked the position of LPZ and inserted a plastic casing that fit closely inside the tank and: (4) LPZ soils were then added to the casing using a funnel; (5) we removed the plastic casing once the LPZ and surrounding transmissive soil was packed (6) transmissive soil was pack above the LPZ and the top of the tank was reassembled. 
The 2D-tank was initially dry-packed by hand to yield a bulk density of approximately $1.76 \mathrm{~kg} \mathrm{~m}^{-3}$ for transmissive zone and $1.57 \mathrm{~kg} \mathrm{~m}^{-3}$ for the LPZ. The packed systems had an approximate average porosity of 0.38 and a total pore volume (PV) of $\sim 481 \mathrm{~cm}^{3}$.

Sample Collection Protocol. To quantify ${ }^{14} \mathrm{C}$-activity in experiments not using $\mathrm{MnO}_{4}^{-}$(i.e., Exp. 2B-2D), effluent samples were transferred directly into a 7-mL scintillation vial containing $5 \mathrm{~mL}$ of Ultima Gold ${ }^{\mathrm{TM}}$ scintillation cocktail (Packard, Meriden, CT). For experiments that used an oxidant flood (i.e., Exps. 2A, 2E-2F) and a background treatment (i.e., Exp. 2D), $3 \mathrm{~mL}$ samples were withdrawn into a 5 - $\mathrm{mL}$ glass syringe. This sample was then quickly distributed into three equal $1 \mathrm{~mL}$ aliquots (labeled Portions A, B, and C) and analyzed using the procedures modified from Kriegman-King and Reinhard, (1992). In brief, Portion A was transferred to a 7-mL scintillation vial that contained $0.3 \mathrm{~mL}$ of $2.67 \mathrm{~N} \mathrm{HNO}_{3}$; Portion $\mathrm{B}$ was transferred into a scintillation vial containing $0.3 \mathrm{~mL}$ of $2.67 \mathrm{~N} \mathrm{NaOH}$; and Portion $\mathrm{C}$ was transferred to a vial containing $0.3 \mathrm{~mL}$ of $2.67 \mathrm{~N} \mathrm{HNO}_{3}$ and quickly transferred to a vial containing $5 \mathrm{~mL}$ of Ultima Gold $^{\mathrm{TM}}$ scintillation cocktail (Packard, Meriden, CT). Portions A and B were purged with $\mathrm{N}_{2}$ gas for $10 \mathrm{~min}$ to release $\mathrm{CO}_{2}$, TCE, and volatile degradates from solution. Then, 5 $\mathrm{mL}$ of scintillation cocktail was added and portions $A$ and $B$ were counted. All samples were mixed on a vortex mixer prior to analysis and ${ }^{14} \mathrm{C}$-activity was determined by liquid scintillation counting (LSC) using a Packard 1900TR liquid scintillation counter (Packard instrument Co., Downers Grove, IL). The ${ }^{14} \mathrm{C}$-activity in Portion A was equivalent to the ${ }^{14} \mathrm{C}$-non volatiles while the activity in Portion $\mathrm{B}$ was equivalent to the total amount of oxidized TCE (i.e., ${ }^{14} \mathrm{CO}_{2}+{ }^{14} \mathrm{C}$-non volatiles). The ${ }^{14} \mathrm{CO}_{2}$ content was calculated by subtracting the activities of Portion A from Portion $\mathrm{B}$. The amount of ${ }^{14} \mathrm{C}$-TCE recovered was calculated by subtracting the activities of Portion A from Portion C (Kriegman-King and Reinhard, 1992). 
Determination of Sweeping Efficiency. To compare the ability of xanthan to increase the penetration of $\mathrm{MnO}_{4}^{-}$into the low permeable zone (LPZ), we visually observed the movement of flooding solutions into the 2D-tank. The term sweeping efficiency is generally used in the remedial amendment literature (Neil et al., 1983; Zhong et al., 2008; Silva et al., 2012). We report the sweeping efficiency of the LPZ as a function of pore volume (e.g., Fig. SI-6). Sweeping efficiency was qualitatively defined as the percentage of the swept area divided by the total area.

Areal sweep is determined by overlaying the template consisted of multiple square grids onto the photo of 2D-Tank captured in each individual pore volume. Due to the double layer of glass plates on the sides of the 2D-tank, we were unable to differentiate color pixels digitally. We therefore, created square grids (1/8" x 1/8") inside a 5" $\times 8$ " rectangular shape which is the same size as 2D-Tank. The transmissive zone contains 2072 grids while the LPZ contains 648 grids. We used these grids as a template. Permanganate has a distinct purple color. If a grid was completely occupied by the flooding solution, it would be counted as one grid. If a grid was partially occupied, it was given a score of $0.25,0.50$, or 0.75 .

For example, if the areal sweep of the transmissive zone was equivalent to $1,500.25$ grids, the sweeping efficiency of this zone is $72.41 \%(1500.25 / 2072 \times 100 \%)$. If the areal sweep of the LPZ was equivalent to 345.75 grids, the sweeping efficiency of this zone is $53.36 \%(345.75 / 648 \times 100 \%)$.

Model Implementation. A Computational Fluid Dynamic (CFD) package in Comsol Multiphysics software (version 4.3a) was used to solve the coupled flow problem (Eqs. 1-6). The constant velocity boundary condition was applied for the inlet boundary. The outlet boundary combined a no viscose stress boundary condition with zero pressure at the top right corner. The Solute Transport in Porous Medium Module in Comsol Multiphysics 4.3a was applied to solve the transport equations (Eqs. 7-8). Inlet 
concentration boundary conditions were set as time dependent concentration boundary conditions for each species based on the procedure of each experiment. The outlet boundary was considered as an outflow where all species mass were transported out of the domain.

An adaptive mesh refinement technique was necessary to ensure the numerical stability of the problem. In this technique, the elements at the interface of reaction were dynamically discretized to smaller sizes as computation progressed. The fully coupled direct numerical solver was used to solve the flow model, where the Jacobian matrix was set to update every iteration. The computational model was implemented to simulate experimental results from transport experiments $2 \mathrm{E}$ and $2 \mathrm{~F}$ (Tables $1, \mathrm{~S} 2$ ). It took $15 \mathrm{~h}$ to simulate Experiment $2 \mathrm{E}$ and $30 \mathrm{~h}$ to simulate Experiment $2 \mathrm{~F}$ on a Dell OptiPlex 9010 computer (32GB RAM, $3^{\text {rd }}$ Gen Intel Core $^{\text {TM }}$ i7-3770).

\section{RESULTS AND DISCUSSION}

Temporal Stability of $\mathrm{MnO}_{4}^{-}-$Xanthan Solutions. To quantify the stability of the xanthan- $\mathrm{MnO}_{4}{ }^{-}$solutions, temporal changes in measured viscosity-shear rate values were periodically recorded over $9 \mathrm{~d}$ (Fig. SI-2). Result showed xanthan alone was relatively stable with minor decreases in apparent viscosities with time (Fig. SI-2A). When $\mathrm{MnO}_{4}^{-}$was mixed with $500 \mathrm{mg} \mathrm{L}^{-1}$ xanthan, either at concentrations of 2500 or $10000 \mathrm{mg} \mathrm{L}^{-1}$, viscosities significantly declined with increased holding times. This was especially evident in the non-Newtonian flow regime (i.e., $>10 \mathrm{~s}^{-1}$ ) and at the higher versus lower $\mathrm{MnO}_{4}^{-}$concentration (i.e., 10000 vs. $2500 \mathrm{mg} \mathrm{L}^{-1}$; Fig. SI-2C, SI-2B). Possible reasons for this decline include the oxidation of xanthan by $\mathrm{MnO}_{4}{ }^{-}$and production of byproducts such as $\mathrm{MnO}_{2}$. When we conducted a parallel experiment where $\mathrm{MnO}_{4}{ }^{-}$concentrations were monitored in xanthan- $\mathrm{MnO}_{4}{ }^{-}$solutions for up to $15 \mathrm{~d}$, 
results showed slight decreases in $\mathrm{MnO}_{4}{ }^{-}$concentrations (Fig. SI-3) and brownish $\mathrm{MnO}_{2}$ precipitates observed in the experimental units (Fig. SI-4).

High viscosity reduces the mobility of the fluid in the higher permeability strata, which in turn promotes cross-flow into adjacent strata of lower permeability (Silva et al., 2012). The instability of xanthan with holding times could hinder the xanthan- $\mathrm{MnO}_{4}{ }^{-}$ solutions from creating cross-flow between layers of different porosities (i.e., different shear rates). Given that the higher the viscosity difference $(\Delta \mu)$, the better the xanthan performs in penetrating low permeable zones, we calculated viscosity differences at shear rates of 3 and $200 \mathrm{~s}^{-1}$, rather than concentrating on declines in viscosity at one shear rate. When the viscosity-shear rate relationship was measured immediately $(T=0$ d), a $46 \mathrm{cP}$ difference $(\Delta \mu)$, was observed for the xanthan solution (Fig. SI-2A). By $T=9$ d, $\Delta \mu$ of the xanthan solution had dropped to $29 \mathrm{cP}$. This decrease indicates some instability that may be due to biodegradation, which has previously been shown to reduce viscosity (Littmann, 1988; Martel et al., 1998; Robert et al., 2006). By comparison, $\Delta \mu$ of solutions containing $\mathrm{MnO}_{4}^{-}$(both 2500 and $10000 \mathrm{mg} \mathrm{L}^{-1}$ ) showed significant decreases when holding times were longer than $12 \mathrm{~h}$. For instance, at $\mathrm{T}=9$ d, $\Delta \mu$ decreased to $6.72 \mathrm{cP}$, an $82.5 \%$ decrease (Fig. SI-2C).

To illustrate how holding times of xanthan- $\mathrm{MnO}_{4}{ }^{-}$solutions can influence the penetration of $\mathrm{MnO}_{4}^{-}$into low permeable zones (LPZ), we compared the sweeping efficiency of a freshly prepared xanthan- $\mathrm{MnO}_{4}{ }^{-}$solution to one that had been held for 24 $\mathrm{h}$ before being injected into our transport tank. Results showed that the freshly prepared $\mathrm{MnO}_{4}^{-}$-xanthan solution delivered $\mathrm{MnO}_{4}{ }^{-}$into the $\mathrm{LPZ}$ (Fig. SI-5A) but the aged xanthan$\mathrm{MnO}_{4}{ }^{-}$solution could not penetrate the $\mathrm{LPZ}$ after a similar number of pore volumes had been delivered (Fig. SI-5B). Even though xanthan- $\mathrm{MnO}_{4}{ }^{-}$solutions have been shown to preserved 60 to $95 \%$ of their viscosity after $72 \mathrm{~h}$ (Smith et al., 2008), results under our experimental conditions (i.e., soil textures, flow rate, and $\mathrm{MnO}_{4}^{-}$concentrations) 
indicated that xanthan- $\mathrm{MnO}_{4}{ }^{-}$solutions needed to be used within a few hours after mixing. A recent publication by Zhong et al. (2013) also demonstrates that a number of site factors such as soil type and water chemistry can contribute to viscosity losses of xanthan solutions during transport and that these factors should be considered before field use. 
Table S1. Chemical properties

\begin{tabular}{|c|c|c|c|c|c|c|c|}
\hline Chemical & $\begin{array}{l}\text { Molecular } \\
\text { Formula }\end{array}$ & Description & $\begin{array}{c}\text { M.W. } \\
\left(\mathrm{g} \mathrm{mol}^{-1}\right)\end{array}$ & $\begin{array}{l}\text { Density } \\
\left(\mathrm{g} \mathrm{cm}^{-3}\right)\end{array}$ & $\begin{array}{c}\text { Viscosity } \\
\text { (cP) }\end{array}$ & $\begin{array}{l}\text { Solubility } \\
\left(\mathrm{mg} \mathrm{L}^{-1}\right)\end{array}$ & Manufacturer \\
\hline $\begin{array}{l}\text { Trichloroethene } \\
\text { (TCE) }\end{array}$ & $\mathrm{C}_{2} \mathrm{HCl}_{3}$ & Contaminant & 131.39 & $1.48^{(1)}$ & $0.58^{(2)}$ & $1101^{(1)}$ & $\begin{array}{l}\text { Sigma Aldrich } \\
\text { (ACS grade) }\end{array}$ \\
\hline Xanthan gum & $\underset{\text { (monomer) }}{\left(\mathrm{C}_{35} \mathrm{H}_{49} \mathrm{O}_{29}\right)_{\mathrm{n}}}$ & Soluble polymer & $\underset{\text { (monomer) }}{(933)_{n}}$ & $0.998^{(3)}$ & Variable & $>5000^{(3)}$ & Sigma Aldrich \\
\hline $\begin{array}{l}\text { Sodium } \\
\text { Permanganate }\end{array}$ & $\mathrm{NaMnO}_{4}$ & Oxidizing agent & 141.93 & 1.972 & - & Liquid & Aldrich Chemistry \\
\hline
\end{tabular}

${ }^{(1)}$ Seol et al., 2001; (2)Imhoff, 1992; and ${ }^{(3)}$ Martel et al., 1998

Table S2: Solutions, concentrations, and pore volumes used in transport experiments

\begin{tabular}{|c|c|c|c|c|c|c|c|c|c|}
\hline \multirow[b]{2}{*}{ Type } & \multirow[b]{2}{*}{ Exp } & \multirow[b]{2}{*}{$\begin{array}{l}\text { Initial Flood } \\
\text { Type }\end{array}$} & \multicolumn{2}{|l|}{$\begin{array}{l}\text { Initial } \\
\text { Flood }\end{array}$} & \multicolumn{2}{|c|}{$\begin{array}{c}\text { Secondary } \\
\text { Flood }\end{array}$} & \multicolumn{2}{|c|}{ Displacement Flood } & \multirow[b]{2}{*}{$\begin{array}{l}\text { Total } \\
\text { PV }\end{array}$} \\
\hline & & & $\begin{array}{l}\text { Solution, } \\
\left(\mathrm{mg} \mathrm{L}^{-1}\right)\end{array}$ & PV & $\begin{array}{l}\text { Solution, } \\
\left(\mathrm{mg} \mathrm{L}^{-1}\right)\end{array}$ & PV & $\begin{array}{l}\text { Solution, } \\
\left(\mathrm{mg} \mathrm{L}^{-1}\right)\end{array}$ & PV & \\
\hline \multirow{6}{*}{ 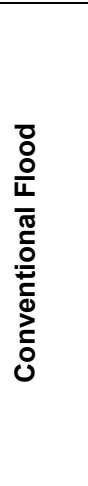 } & $1 \mathrm{~A}$ & Water-Polymer & $\begin{array}{c}\text { Red-CaCl } 2,{ }^{1}(441) \\
\text { Xanthan }(500)\end{array}$ & 2.00 & $\mathrm{~N} / \mathrm{A}$ & $\mathrm{N} / \mathrm{A}$ & $\mathrm{N} / \mathrm{A}$ & N/A & 2.00 \\
\hline & $1 \mathrm{~B}$ & Oxidant & $\mathrm{MnO}_{4}^{-},(4000)$ & 2.00 & $\mathrm{~N} / \mathrm{A}$ & $\mathrm{N} / \mathrm{A}$ & $\mathrm{N} / \mathrm{A}$ & $\mathrm{N} / \mathrm{A}$ & 2.00 \\
\hline & $1 \mathrm{C}$ & Oxidant & $\mathrm{MnO}_{4}^{-},(4000)$ & 0.50 & $\begin{array}{l}\mathrm{CaCl}_{2} \\
(441)\end{array}$ & 1.50 & $\mathrm{~N} / \mathrm{A}$ & N/A & 2.00 \\
\hline & $1 \mathrm{D}$ & Oxidant - Polymer & $\begin{array}{l}\mathrm{MnO}_{4}^{-},(4000) ; \\
\text { Xanthan (250) }\end{array}$ & 0.50 & $\begin{array}{l}\mathrm{CaCl}_{2} \\
(441)\end{array}$ & 1.50 & $\mathrm{~N} / \mathrm{A}$ & N/A & 2.00 \\
\hline & $1 \mathrm{E}$ & Oxidant - Polymer & $\begin{array}{l}\mathrm{MnO}_{4}^{-},(4000) ; \\
\text { Xanthan, (500) }\end{array}$ & 0.50 & $\begin{array}{l}\mathrm{CaCl}_{2}, \\
(441)\end{array}$ & 1.50 & $\mathrm{~N} / \mathrm{A}$ & N/A & 2.00 \\
\hline & $1 \mathrm{~F}$ & Oxidant - Polymer & $\begin{array}{c}\mathrm{MnO}_{4}^{-},(4000) \\
\text { Xanthan, }(1000)\end{array}$ & 0.50 & $\begin{array}{l}\mathrm{CaCl}_{2} \\
(441)\end{array}$ & 1.50 & $\mathrm{~N} / \mathrm{A}$ & N/A & 2.00 \\
\hline \multirow{6}{*}{  } & $2 \mathrm{~A}$ & Oxidant - Polymer & $\begin{array}{c}\mathrm{MnO}_{4}^{-},(10000)^{2} \\
\text { Xanthan, }(500)\end{array}$ & 0.25 & $\begin{array}{l}\mathrm{CaCl}_{2} \\
(441)\end{array}$ & 2.75 & $\begin{array}{l}\text { Xanthan, } \\
(500)\end{array}$ & 1.50 & 4.50 \\
\hline & $2 \mathrm{~B}$ & Water & Red-CaCl $2,(441)$ & 0.25 & $\begin{array}{l}\text { Red- }-\mathrm{CaCl}_{2} \\
\quad(441)\end{array}$ & 2.75 & $\mathrm{H}_{2} \mathrm{O}$ & 1.50 & 4.50 \\
\hline & $2 \mathrm{C}$ & Water & Red-CaCl 2 , (441) & 0.25 & $\begin{array}{l}\text { Red- } \mathrm{CaCl}_{2} \\
\quad(441)\end{array}$ & 2.75 & $\begin{array}{l}\text { Xanthan, } \\
(500)\end{array}$ & 1.50 & 4.50 \\
\hline & $2 \mathrm{D}$ & Water - Polymer & $\begin{array}{l}\text { Red-CaCl }{ }_{2},(441) \\
\text { Xanthan, }(500)\end{array}$ & 0.25 & $\begin{array}{c}\text { Red-CaCl} \\
(441)\end{array}$ & 2.75 & $\begin{array}{l}\text { Xanthan, } \\
(500)\end{array}$ & 1.50 & 4.50 \\
\hline & $2 \mathrm{E}$ & Oxidant & $\mathrm{MnO}_{4}^{-},(10000)$ & 0.25 & $\begin{array}{l}\mathrm{CaCl}_{2} \\
(441)\end{array}$ & 2.75 & $\begin{array}{l}\text { Xanthan, } \\
(500)\end{array}$ & 1.50 & 4.50 \\
\hline & $2 \mathrm{~F}$ & Oxidant - Polymer & $\begin{array}{l}\mathrm{MnO}_{4}^{-},(10000) ; \\
\text { Xanthan, }(500)\end{array}$ & 0.25 & $\begin{array}{l}\mathrm{CaCl}_{2} \\
(441)\end{array}$ & 2.75 & $\begin{array}{l}\text { Xanthan, } \\
(500)\end{array}$ & 1.50 & 4.50 \\
\hline
\end{tabular}

\footnotetext{
${ }^{1} \mathrm{Red}-\mathrm{CaCl}_{2}$ is a $\mathrm{CaCl}_{2}$ solution dyed red for visual tracking. ${ }^{2}$ Xanthan solution was prepared overnight.
} 
Table S3. Model parameters used in simulations

\begin{tabular}{|c|c|c|}
\hline Parameter/Property & Unit & Value \\
\hline \multicolumn{3}{|l|}{ Fluid properties } \\
\hline Flow rate & $m^{3} s^{-1}$ & $5 \times 10^{-8}$ \\
\hline Density & $\mathrm{kg} \mathrm{m}^{-3}$ & 1002 \\
\hline Polymer initial concentration & $\mathrm{kg} \mathrm{m}^{-3}$ & 0.5 \\
\hline Permanganate initial concentration & $\mathrm{kg} \mathrm{m}^{-3}$ & 10 \\
\hline TCE initial concentration & $\mathrm{kg} \mathrm{m}^{-3}$ & 0.5 \\
\hline \multicolumn{3}{|l|}{ Soil properties } \\
\hline \multicolumn{3}{|l|}{ Transmissive zone } \\
\hline Permeability* & $\mathrm{m}^{2}$ & $3.9 \times 10^{-10}$ \\
\hline Porosity & & 0.37 \\
\hline Dispersivity & $\mathrm{m}$ & 0.00155 \\
\hline$d_{50}$ & $\mathrm{~m}$ & $7.13 \times 10^{-4}$ \\
\hline \multicolumn{3}{|l|}{ Low permeable zone } \\
\hline Permeability & $\mathrm{m}^{2}$ & $5 \times 10^{-11}$ \\
\hline Porosity & & 0.42 \\
\hline Dispersivity & $\mathrm{m}$ & 0.000752 \\
\hline$d_{50}$ & $\mathrm{~m}$ & $5.09 \times 10^{-4}$ \\
\hline \multicolumn{3}{|l|}{ Reaction rate constant } \\
\hline \multicolumn{3}{|l|}{$2 E$ experiment } \\
\hline Transmissive zone $\left(k_{T Z}\right)$ & $\mathrm{m}^{3} \mathrm{~kg}^{-1} \mathrm{~s}^{-1}$ & $7 \times 10^{-5}$ \\
\hline Low permeable zone $\left(k_{L P Z}\right)$ & $\mathrm{m}^{3} \mathrm{~kg}^{-1} \mathrm{~s}^{-1}$ & $5 \times 10^{-4}$ \\
\hline \multicolumn{3}{|l|}{$2 F$ experiment } \\
\hline Transmissive zone $\left(k_{T Z}\right)$ & $\mathrm{m}^{3} \mathrm{~kg}^{-1} \mathrm{~s}^{-1}$ & $2.64 \times 10^{-4}$ \\
\hline Low permeable zone $\left(k_{L P Z}\right)$ & $\mathrm{m}^{3} \mathrm{~kg}^{-1} \mathrm{~s}^{-1}$ & $1.2 \times 10^{-3}$ \\
\hline \multicolumn{3}{|l|}{ Viscosity parameters } \\
\hline \multicolumn{3}{|l|}{ Xanthan $\left(500 \mathrm{mg} \mathrm{L}^{-1}\right)$} \\
\hline a & $\mathrm{cP}$ & 97.711 \\
\hline $\mathrm{b}$ & & -0.25 \\
\hline$\mu_{\circ}$ & $\mathrm{cP}$ & 175.39 \\
\hline$\mu_{\infty}$ & $\mathrm{cP}$ & 1.002 \\
\hline \multicolumn{3}{|c|}{ Xanthan $\left(500 \mathrm{mg} \mathrm{L}^{-1}\right)+\mathrm{MnO}_{4}^{-}\left(10000 \mathrm{mg} \mathrm{L}^{-1}\right)$} \\
\hline a & $\mathrm{cP}$ & 450 \\
\hline b & & -0.19 \\
\hline$\mu_{\circ}$ & $\mathrm{cP}$ & $87.6^{*} \mathrm{C}_{2}+240$ \\
\hline$\mu_{\infty}$ & $\mathrm{cP}$ & 1.002 \\
\hline
\end{tabular}

${ }^{*}$ Estimated using Karman-Cozeny equation; $\mathrm{C}_{2}$ is $\mathrm{MnO}_{4}{ }^{-}$concentration $\left(\mathrm{kg} \mathrm{m}^{-3}\right)$ 


\section{Effluent Ports}

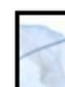

Figure SI-1. Schematic of 2D-tank dimensions 




342

343

344

Figure SI-2. Temporal changes in viscosity-shear rate relationships for $(A)$ xanthan, $(B)$ xanthan $+2500 \mathrm{mg} \mathrm{MnO}_{4}{ }^{-} \mathrm{L}^{-1} ;(\mathrm{C})$ xanthan $+10000 \mathrm{mg} \mathrm{MnO}_{4}{ }^{-} \mathrm{L}^{-1}$. 


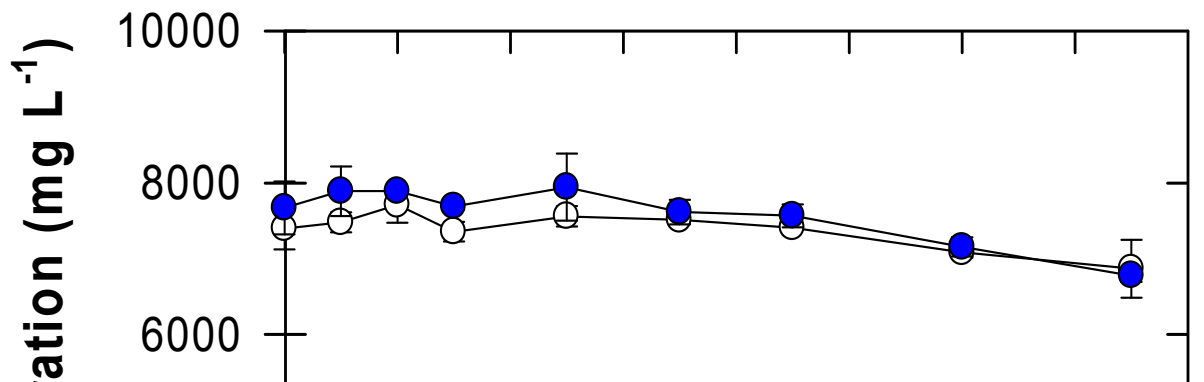

$\left[\mathrm{MnO}_{4}{ }^{-}\right.$: Xanthan] $\diamond$ [1100: 250] mgL ${ }^{-1}$ $\checkmark$ [1100: 500] $\mathrm{mgL}^{-1}$ $\square$ [2200: 250] $\mathrm{mgL}^{-1}$ $\square$ [2200: 500] $\mathrm{mgL}^{-1}$ $\triangle$ [4400: 250] $\mathrm{mgL}^{-1}$ $\triangle$ [4400: 500] $\mathrm{mgL}^{-1}$ [7700: 250] $\mathrm{mgL}^{-1}$ - [7700: 500] $\mathrm{mgL}^{-1}$

Figure SI-3. Temporal changes in $\mathrm{MnO}_{4}{ }^{-}$concentration for various $\mathrm{MnO}_{4}{ }^{-}$-xanthan ratios. 
Figure SI-4. Photographic evidence of $\mathrm{MnO}_{2}$ formation observed in xanthan- $\mathrm{MnO}_{4}{ }^{-}$ solution. 

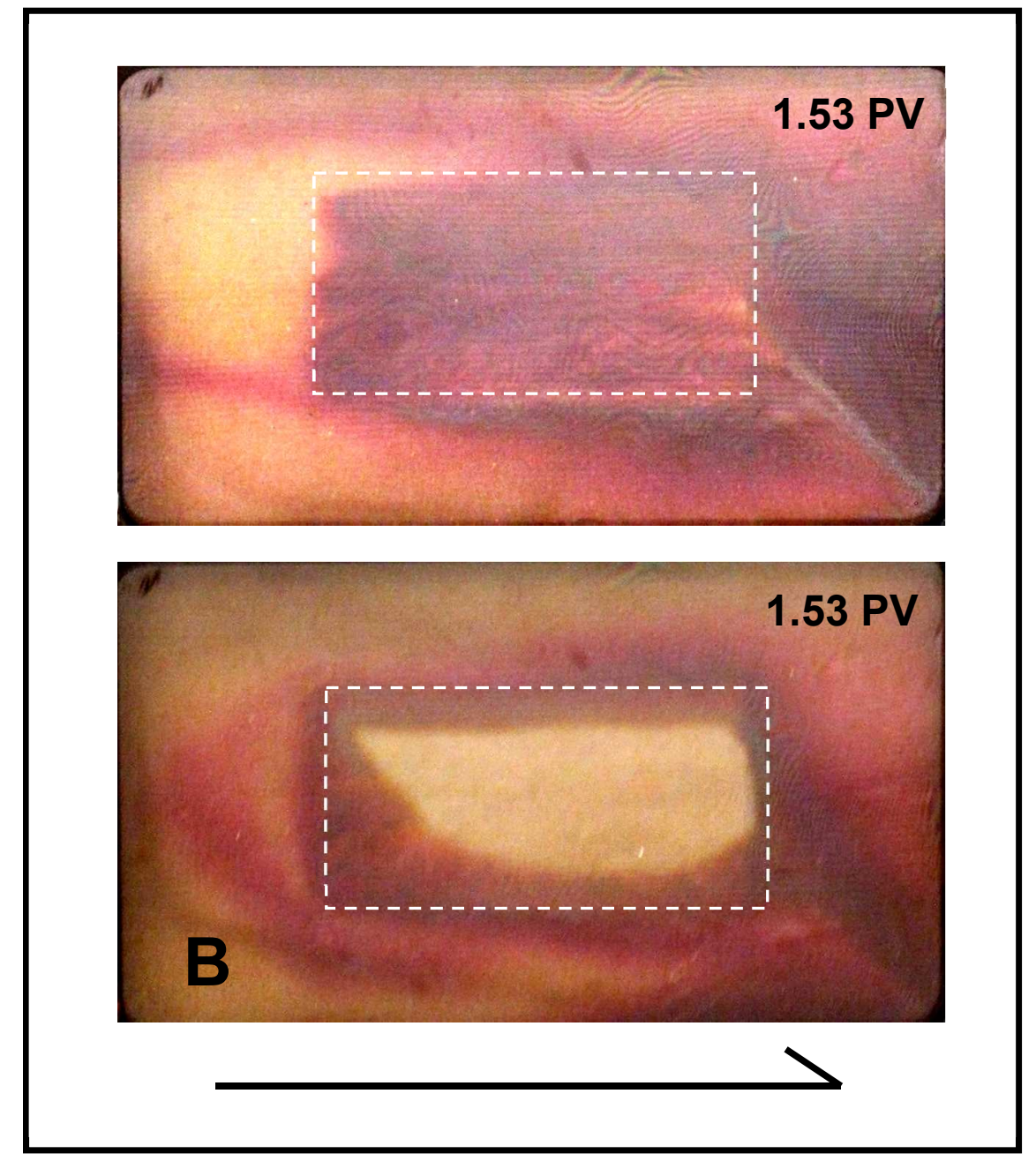

Figure SI-5. Photographs of 2D tank following initial floods with (A) xanthan $+500 \mathrm{mg}$ $\mathrm{MnO}_{4}{ }^{-} \mathrm{L}^{-1}$; and $(\mathrm{B})$ xanthan $+500 \mathrm{mg} \mathrm{MnO}_{4}{ }^{-} \mathrm{L}^{-1}$ aged for $24 \mathrm{~h}$. 



446

Figure SI-6. Sweeping efficiencies of (A) conventional flooding experiments (Exps. 1C- 




$$
\mathrm{MnO}_{4}^{-} \text {: Xanthan (mg L-1) }
$$

Figure SI-7. Solution densities of various combinations of $\mathrm{MnO}_{4}{ }^{-}$and xanthan concentrations. Error bars indicate sample standard deviations $(n=7)$. 


\begin{tabular}{|c|c|c|c|c|c|c|c|c|}
\hline \multirow{2}{*}{$\begin{array}{l}\text { Multistep } \\
\text { Treatment }\end{array}$} & \multicolumn{8}{|c|}{ Pore Volume } \\
\hline & 0.19 & 0.57 & 1.05 & 1.53 & 2.04 & 3.06 & 3.93 & 4.50 \\
\hline $\begin{array}{c}\text { Exp. 2A } \\
\mathrm{MnO}_{4}+ \\
\text { Xanthan } \mathrm{Aged}^{+}(0.25 \mathrm{PV} \\
\mathrm{CaCl}_{2}(2.75 \mathrm{PV}) \\
\text { Xanthan }(1.50 \mathrm{PV})\end{array}$ & & & & & & & & \\
\hline $\begin{array}{c}\text { Exp. 2B } \\
\text { Red-CaCl}(0.25 \mathrm{PV}) \\
\text { Red-CaCl}(2.75 \mathrm{PV}) \\
\mathrm{H}_{2} \mathrm{O}(1.50 \mathrm{PV})\end{array}$ & & & & & & & & \\
\hline $\begin{array}{c}\text { Exp. 2C } \\
\text { Red-CaCl} 2 \text { (0.25 PV); } \\
\text { Red-CaCl }(2.75 \mathrm{PV}) \\
\text { Xanthan (1.50 PV) }\end{array}$ & & & & & & & 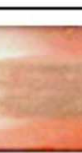 & \\
\hline $\begin{array}{c}\text { Exp. 2D } \\
\text { Red-CaCl} \\
+ \text { Xanthan }(0.25 \mathrm{PV}) \\
\text { Red-CaCl }(2.75 \mathrm{PV}) \\
\text { Xanthan }(1.50 \mathrm{PV})\end{array}$ & & & & & & & & \\
\hline $\begin{array}{c}\text { Exp. 2E } \\
\mathrm{MnO}_{4}(0.25 \mathrm{PV}) \\
\mathrm{CaCl}_{2}(2.75 \mathrm{PV}) \\
\text { Xanthan (1.50 PV) }\end{array}$ & & & & & & & & \\
\hline $\begin{array}{c}\text { Exp. 2F } \\
\mathrm{MnO}_{4}+ \\
\text { Xanthan }(0.25 \mathrm{PV}) ; \\
\mathrm{CaCl}_{2}(2.75 \mathrm{PV}) \\
\text { Xanthan }(1.50 \mathrm{PV})\end{array}$ & & & & & & & & \\
\hline
\end{tabular}

Figure SI-8. Time-lapse photography of multistep flooding experiments (Exps. 2A-2F). 

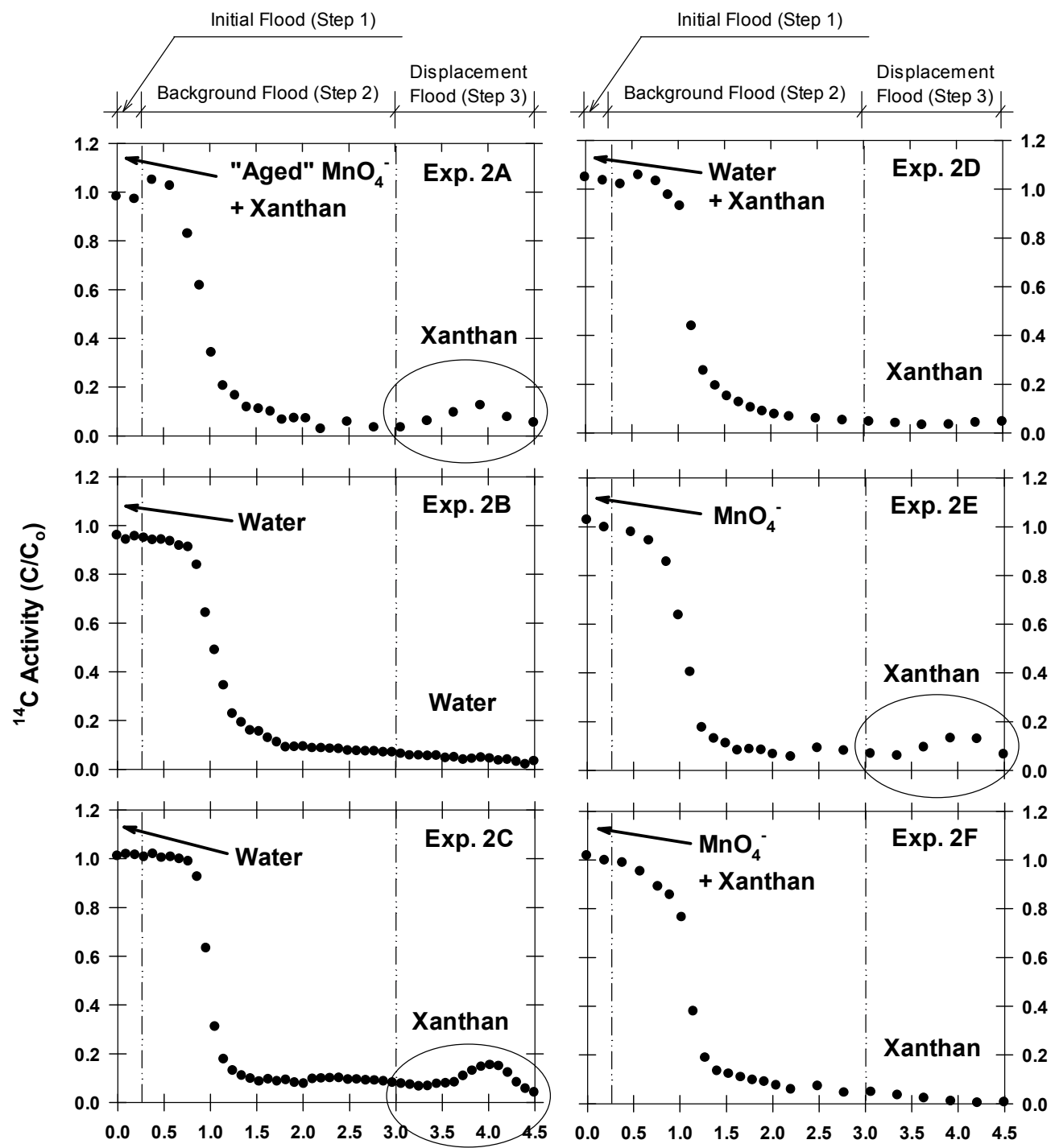

Figure SI-9. ${ }^{14} \mathrm{C}$-effluent breakthrough curves following multistep flood treatments. 


\section{REFERENCES}

Chen, C.S.H., Sheppard, E.W., Conformation and hydrolytic stability of polysaccharide from xanthomonas-campestris. J. Macromol. Sci. Chem. 1979, 13, 239-259.

Chokejaroenrat, C., Comfort, S.D., Harris, C.E., Snow, D.D., Cassada, D., Sakulthaew, C., Satapanajaru, T., Transformation of hexahydro-1,3,5-trinitro-1,3,5-triazine (RDX) by permanganate. Environ. Sci. Technol. 2011, 45, 3643-3649.

Imhoff, P.T. Dissolution of a nonaqueous phase liquid in saturated porous media, Ph.D. dissertation, Princeton University, Princeton, NJ, 1992

Kriegman-King, M.R., Reinhard, M. Transformation of carbon tetrachloride in the presence of sulfide, biotite, and vermiculite. Environ. Sci. Technol. 1992, 26, 2198-2206.

Littmann, W. Polymer Flooding. Elsevier Science Publishers, New York, NY. 1988.

Martel, K.E., Martel, R., Lefebvre, R., Gelinas, P.J. Laboratory study of polymer solutions used for mobility control during in situ NAPL recovery. Ground Water Monit. R. 1998, 18, 103-113.

Neil, J.D., Chang, H.L., Geffen, T.M. Waterflooding and improved waterflooding. In Improved Oil Recovery; Bond, D.C., Hocott, C.R. Poettmann, F.H., (Eds.), Interstate Oil Compact Commission, Oklahoma City, OK, 1983.

Robert, T., Martel, R., Conrad, S.H., Lefebvre, R., Gabriel, U. Visualization of TCE recovery mechanisms using surfactant-polymer solutions in a two-dimensional heterogeneous sand model. J. Contam. Hydrol. 2006, 86, 3-31.

Sale, T.C., Zimbron, J.A., Dandy, D.S. Effects of reduced contaminant loading on downgradient water quality in an idealized two-layer granular porous media. $\mathrm{J}$. Contam. Hydrol. 2008, 102, 72-85. 
Seol, Y., Schwartz, F.W., Lee, S. Oxidation of binary dnapl mixtures using potassium permanganate with a phase transfer catalyst. Ground Water Monit. R. 2001, 21, 124-132.

Silva, J.A.K., Smith, M.M., Munakata-Marr, J., McCray, J.E. The effect of system variables on in situ sweep-efficiency improvements via viscosity modification. $J$. Contam. Hydrol. 2012, 136, 117-130.

Smith, M.M., Silva, J.A.K., Munakata-Marr, J., McCray, J.E.,. Compatibility of polymers and chemical oxidants for enhanced groundwater remediation. Environ. Sci. Technol. 2008, 42, 9296-9301.

Zhong, L., Oostrom, M., Truex, M.J., Vermeul, V.R., Szecsody, J.E. Rheological behavior of xanthan gum solution related to shear thinning fluid delivery for subsurface remediation. J. Hazard. Mater. 2013, 244-245, 160-170.

Zhong, L., Oostrom, M., Wietsma, T.W., Covert, M.A. Enhanced remedial amendment delivery through fluid viscosity modifications: Experiments and numerical simulations. J. Contam. Hydrol. 2008,101, 29-41. 